\title{
Numerical and experimental study on air thrust foil bearing performance with improved structural model based on real-time taper inlet height
}

Fangcheng Xu ( $\sim$ fcxu@dlut.edu.cn)

Dalian University of Technology

Liukai Hou

Beijing Aerospace Propulsion Institute

Bin Wu

Suzhou Dongling Vibration Test Instrument Co., Ltd

Zeda Dong

Dalian University of Technology

Yongliang Wang

Dalian Maritime University

Original Article

Keywords: Air thrust foil bearing, Taper inlet height, Load capacity, Friction torque, Test

Posted Date: July 8th, 2020

DOl: https://doi.org/10.21203/rs.3.rs-40416/v1

License: (c) (i) This work is licensed under a Creative Commons Attribution 4.0 International License.

Read Full License 


\section{Title page}

\section{Numerical and experimental study on air thrust foil bearing performance with improved structural model based on real-time taper inlet height}

Fangcheng Xu, born in 1985, is now an associate professor of School of Control Science and Engineering, Dalian University of Technology and DUT Artificial Intelligence Institute, Dalian, China. His research interests include gas foil bearing, foil seal, rotor dynamics and oil-free turbomachinery.

Tel: +86-13610847587; E-mail: fcxu@dlut.edu.cn

Liukai Hou, born in 1996, is now an engineer of Beijing Aerospace Propulsion Institute, Beijing, China. He received his master degree from Dalian University of Technology, China, in 2020. His research interests include gas foil bearing and rotor dynamics.

Bin Wu, born in 1965, is now a chief engineer of Suzhou Dongling Vibration Test Instrument Co., Ltd, Suzhou, China. His research interests include noise and vibration control.

Zeda Dong, born in 1997, is now a master student of School of Control Science and Engineering, Dalian University of Technology, China. He received his bachelor degree from Dalian Maritime University, China, in 2019. His research interests include gas foil bearing and rotor dynamics.

Yongliang Wang, born in 1983, is now an associate professor of Naval Architecture and Ocean Engineering College, Dalian Maritime University, China. His research interests include gas foil bearing and rotor dynamics.

\section{Corresponding author: Fangcheng Xu E-mail: fcxu@dlut.edu.cn}




\title{
Numerical and experimental study on air thrust foil bearing performance with improved structural model based on real-time taper inlet height
}

\author{
Fang-cheng $\mathrm{Xu}^{1,2} \cdot$ Liu-kai $\mathrm{Hou}^{3} \cdot \mathrm{Bin} \mathrm{Wu}^{4} \cdot$ Ze-da Dong1 $\bullet$ Yong-liang Wang ${ }^{5}$
}

Received July xx, 2022

(c) Chinese Mechanical Engineering Society and Springer-Verlag Berlin Heidelberg 2017

\begin{abstract}
Air thrust foil bearings are key bearings of micro turbo-machinery (such as micro gas turbines, turbo blowers, and air compressors). The bearing load capacity is affected by many factors, and the taper inlet height of bearing structure is closely related to the load capacity. In many previous literature the taper inlet height, as a constant value, was used to calculate film thickness distribution. However, the reality is that the foil will be squeezed by the pressure generated between runner disk and top foil, which makes taper inlet height change during iteration. Therefore, the actual bearing taper inlet height should be chosen properly instead of the constant taper inlet height when iterating. In this paper, an improved computational model of film thickness for adjusting the taper inlet height in real-time is proposed. The relationship between the maximum bearing load capacity and taper inlet height at different rotor speeds of two models is obtained through numerical simulation. It is found that the optimal taper inlet height of the new model is larger than that of the old model. Three types of bearings with different taper inlet height $(20 \mu \mathrm{m}, 70 \mu \mathrm{m}, 114 \mu \mathrm{m})$ had been tested and the maximum load capacity at different rotor speeds had been obtained. Finally, test data and the simulation results of the two models are compared. It is found that the simulation results of the two models are quite different when the taper inlet height is near the optimal taper inlet height, and the new model is more agree well with the test data.
\end{abstract}

\footnotetext{
$\triangle$ Fangcheng Xu

fcxu@dlut.edu.cn

Dalian University of Technology, Dalian 116024, China

DUT Artificial Intelligence Institute, Dalian 116024, China

Beijing Aerospace Propulsion Institute, Beijing 100076, China

4 Suzhou Dongling Vibration Test Instrument Co., Ltd Suzhou, 215163, China

5 Dalian Maritime University, Dalian116026, China
}

Keywords: Air thrust foil bearing, Taper inlet height, Load capacity, Friction torque, Test

\section{Introduction}

The air foil thrust bearing is a kind of bearing that can be applied to a micro-turbo machine, which balances the axial force generated by the pressure difference between the compressor and the turbo-machine [1-4]. Compared with traditional rolling bearings or sliding bearings, air foil thrust bearings have many advantages, such as: no pollution to the environment due to using air as a lubricant; high reliability because it doesn't need a separate oil supply device; high speed and wide temperature range on operating, etc.[5-7]. With the continuous development of technology, the demand for thrust bearings is increasing. Therefore, it is critical to obtain the characteristics of the thrust bearing more accurately.

The development of air foil journal bearings has been relatively mature [8-10]. Later, researchers began to devote themselves to the research of air thrust foil bearings [11-18]. In 1983, Heshmat H. and Walowit J. A. established the foundation model of the bump foil equivalent to spring structure, and gave a calculation model[6]. From then on, the theoretical research on the air foil thrust bearing began. Later, Roger $\mathrm{Ku}[19]$ studied the influence of bearing design parameters on its dynamic stiffness and damping characteristics. In 1999, Iordanoff[20] established a stiffness calculation model that considers the friction of bump structures. The finite difference method is used to solve the gas Reynolds equation, and the analysis of the structure was simplified for faster calculation. In the same year, Heshmat and $\mathrm{Xu}[21]$ used the finite element method and the finite difference method to analyze the bearing characteristics. The pressure distribution and film thickness distribution were simulated and provides a research method for air foil 
bearing.

In some literatures, the models considering foil deformation had been also proposed [5, 22-26]. In 2008, Park D. J. and Kim C. H. etc. studied the influence on air thrust bearing characteristics with tilts and slip flow. At the same time, the influence of different taper inlet heights on bearing load, friction torque, stiffness and damping coefficients are simulated. However, this paper only contains theoretical analysis and lacks relevant test data[24]. Lee and Kim etc. developed a model that predicted deflection with variable axial load. They used deflection of the elastic foundation in the air film height equation. Three types of bearings with different outer radii had been were tested to verify the theoretical model. Nevertheless, this paper didn't research the influence of the taper inlet height on bearing characteristics[25]. In 2015, Andres and Ryu etc. had present the physical analysis and numerical model prediction of the static and dynamic forced performance of air thrust foil bearing. Similarly, the foil deformation had been taken into account in the model. However, this paper doesn't focus on the taper inlet height [26]. In 2017, Kim and Park etc. studied the influence of bearing geometric parameters (taper angle, taper inlet height) on the maximum bearing load capacity. They had found the existence of an optimal taper inlet height when the minimum film thickness is constant or the rotor speed is constant. However, they didn't consider the real-time variation of taper inlet height[22].

The air thrust foil bearing will be damaged if the bearings load capacity can't be predicted accurately. Therefore, it is very important to improve the accuracy of theoretical model in predicting bearing load capacity. In many literatures, the taper inlet height, as a constant value, was used to calculate film thickness distribution. However, the reality is that the foil will be squeezed by the pressure, which makes taper inlet height change during iteration. In order to predict bearing load capacity more accurately, an improved calculation model that can adjust the taper inlet height in real-time has been proposed. Finally, the superiority of the proposed model is proved by test.

\section{Theoretical model}

As in the previous literatures, for this air thrust foil bearings, assuming that the viscosity of the air is constant. An isothermal air model has been used and the pressure has been considered in the gas film according to the ideal gas law $P v=\rho R T$. [6]

Therefore, the steady film flow between the runner disk and the thrust bearing surface can be written as the following dimensionless Reynolds equation:

$$
\frac{1}{\bar{r}} \frac{\partial}{\partial \bar{r}}\left(\bar{r} \cdot \bar{h}^{3} \cdot \bar{p} \frac{\partial \bar{p}}{\partial \bar{r}}\right)+\frac{1}{\bar{r}^{2}} \frac{\partial}{\partial \theta}\left(\bar{h}^{3} \cdot \bar{p} \cdot \frac{\partial \bar{p}}{\partial \theta}\right)=\Lambda \frac{\partial(\bar{p} \cdot \bar{h})}{\partial \theta}
$$

Where:

$$
\begin{gathered}
\Lambda=\left(6 \mu \omega / p_{a}\right)\left(R_{0} / C^{2}\right) \\
\bar{h}=h / C, \bar{r}=r / R_{0}, \bar{p}=p / p_{a}, \bar{g}=g / C
\end{gathered}
$$

The structure design of thrust bearing foil is shown in Fig.1. In addition, the taper inlet height $H_{T}$ of bearing can be changed by adjusting the height of shim. The film thickness between the runner disk and the thrust bearing can be expressed by the following formula:

$$
h=C+g(r, \theta)+w(r, \theta)
$$

Where $C$ is the film gap between runner disk and the thrust bearing trailing edge, $g(r, \theta)$ is the taper height and $w(r, \theta)$ is the foil deformation.

A dimensionless film thickness formula is obtained:

$$
\bar{h}=1+\bar{g}(r, \theta)+\bar{w}(r, \theta)
$$

Where $\bar{h}$ is the dimensionless film thickness, $\bar{g}(r, \theta)$ is the dimensionless taper height, $\bar{w}(r, \theta)$ is the dimensionless foil deformation.

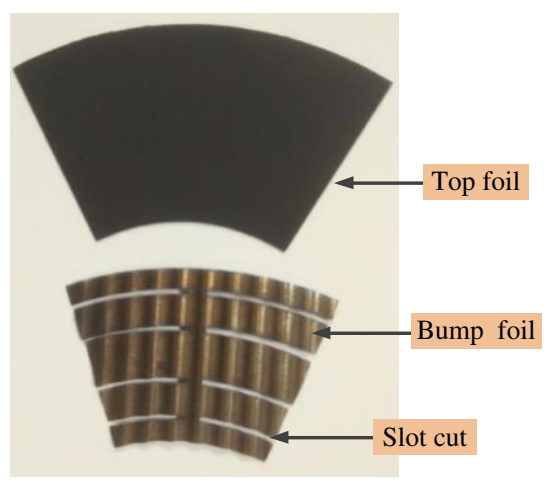

(a)

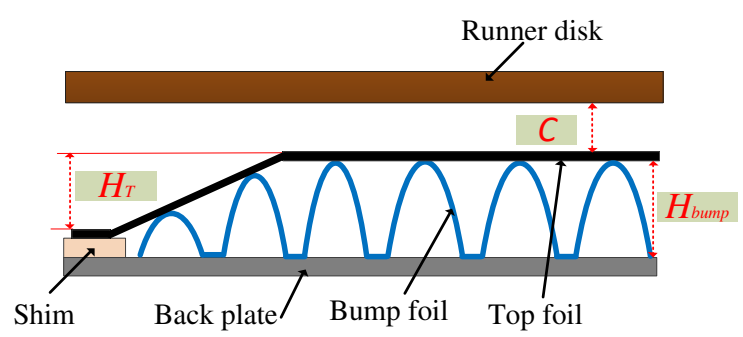

(b) 


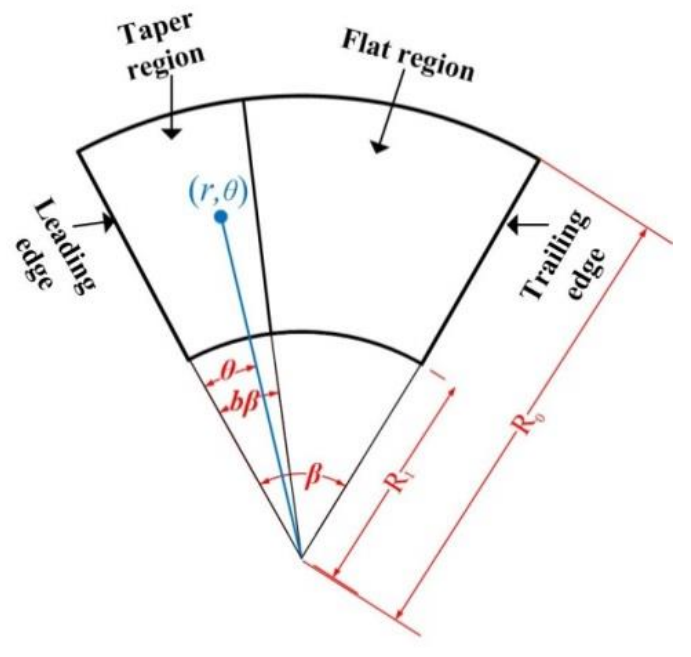

(c)

Fig. 1 Structure design of air thrust foil bearing

In the previous literature, the calculation of the taper height is based on the following formula[5]:

$$
g(\bar{r}, \theta)= \begin{cases}H_{T}\left(1-\frac{\theta}{b \beta}\right), & (0 \leq \theta \leq b \beta)\end{cases}
$$

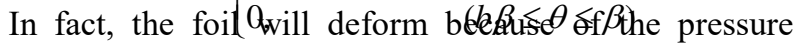
acting on the thrust bearing, which causes directly the taper inlet height $H_{T}$ to change ceaselessly. The schematic diagram is shown in Fig.2. Therefore, the taper inlet height after the change (the taper inlet height after the change is referred to as the actual taper inlet height $H_{\text {actual }}$ ) should be used when iterating, which is closer to the real physical model. The actual taper inlet height is equal the difference between initial taper inlet height and foil deformation.

There:

$$
H_{\text {actual }}=H_{T}-H_{d e}
$$

The model 2 variables describing is as shown in Fig. 3. Therefore, this paper uses the following formula to calculate the distribution of film thickness:

$$
g(\bar{r}, \theta)= \begin{cases}H_{\text {actual }}\left(1-\frac{\theta}{b \beta}\right), & (0 \leq \theta \leq b \beta) \\ 0, & (b \beta \leq \theta \leq \beta)\end{cases}
$$

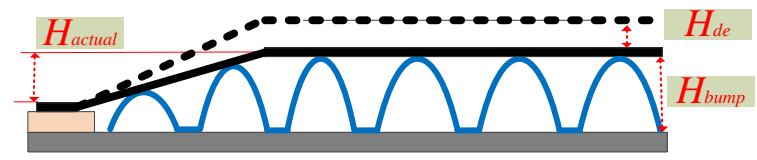

Fig. 2 Schematic Diagram of the model

The boundary conditions of the air thrust foil bearing are:

$$
\begin{cases}r=R_{I}, & r=R_{O} \\ \theta=0, & \theta=\beta \\ p=p_{a} & \end{cases}
$$

The corresponding dimensionless boundary conditions are:

$$
\left\{\begin{array}{cc}
\bar{r}=R_{I} / R_{O}, & \bar{r}=1 \\
\theta=0, & \theta=\beta \\
\bar{p}=1 &
\end{array}\right.
$$

The characteristics of the thrust bearing mainly include the bearing load capacity and friction torque, which can be expressed by the following formula[27]:

$$
W=N \int_{R_{I}}^{R_{o}} \int_{0}^{\beta}\left(p-p_{a}\right) r d \theta d r
$$

$$
T=N \int_{R_{I}}^{R_{o}} \int_{0}^{\beta}\left(\frac{\bar{h}}{2} \frac{\partial p}{\partial \theta} \bar{r}+\frac{\Lambda}{6} \frac{\bar{r}^{3}}{\bar{h}}\right) d \theta d \bar{r}
$$

\section{Runner disk}

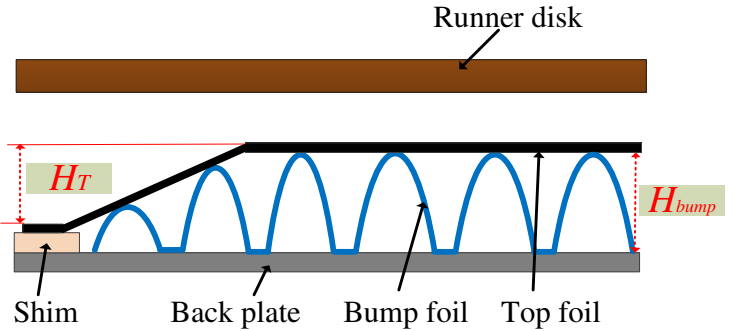




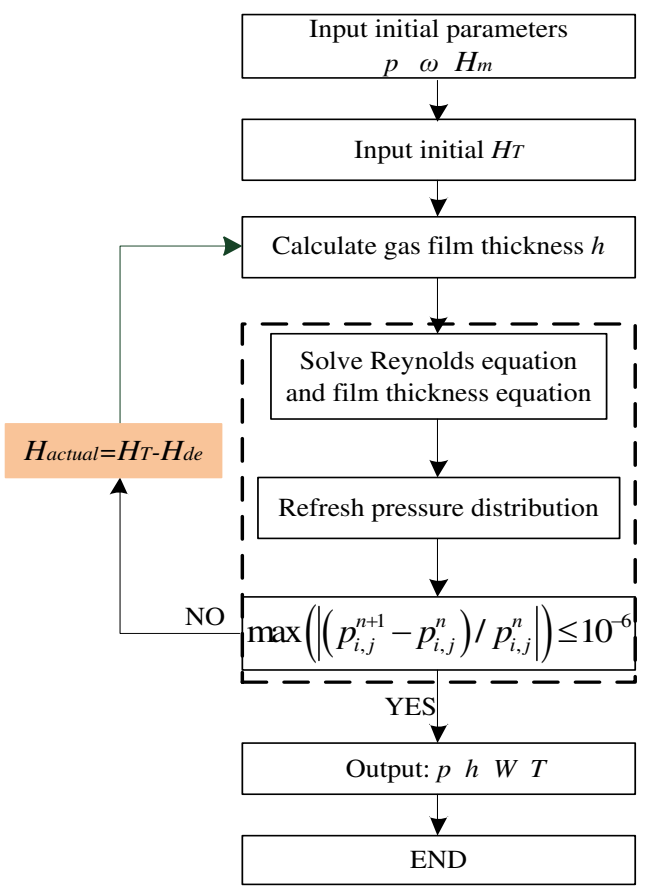

Fig. 3 Code flow chart

The Reynolds equation and the film thickness equation are solved by the finite element method and the finite difference method, and then the pressure distribution and film thickness distribution under steady state conditions will be obtained. The bearing load capacity and friction torque can be calculated by the pressure distribution and film distribution. Write a code to calculate the bearing characteristics, the whole process are shown in Fig. 3. In the iteration process, $H_{T}$ should be replaced by $H_{\text {actual }}$ before calculating the film thickness distribution.

\section{Simulation results and analysis}

Table 1 lists the parameters of air thrust foil bearing for simulation calculation. The thrust bearing outer diameter $R_{O}$ used in the simulation is $72 \mathrm{~mm}$, the inner diameter $R_{I}$ is $18 \mathrm{~mm}$, and the thickness of the top foil $T_{\text {top }}$ is $0.2 \mathrm{~mm}$. The total stiffness of all bump foils $K$ is $11.58 \mathrm{MN} / \mathrm{m}$. The predicted maximum load capacity versus taper inlet height for different rotor speed had been simulated. In this paper, it is considered that the bearing load capacity is the maximum load capacity when the minimum film thickness $H_{m}$ is $4 \mu \mathrm{m}$.

Table 1 Dimensions of thrust bearing for simulation

\begin{tabular}{lc}
\hline Foil bearing parameters & value \\
\hline Bearing inner radium $(\mathrm{mm}), R_{I}$ & 18 \\
Bearing outer radium $(\mathrm{mm}), R_{O}$ & 36 \\
\hline
\end{tabular}

\begin{tabular}{|c|c|c|c|}
\hline Taper ratio, $b$ & \multicolumn{3}{|c|}{0.2564} \\
\hline Pad angle(deg), $\beta$ & \multicolumn{3}{|c|}{58.5} \\
\hline Pad number, $N$ & \multicolumn{3}{|c|}{6} \\
\hline Stiffness of total bump foil (MN/m), $K$ & \multicolumn{3}{|c|}{11.58} \\
\hline Top foil thickness (mm), $T_{t o p}$ & \multicolumn{3}{|c|}{0.2} \\
\hline Young's modulus(GPa), $\quad E$ & \multicolumn{3}{|c|}{800} \\
\hline Taper inlet height $(\mu \mathrm{m}), \quad H_{T}$ & \multicolumn{3}{|c|}{$0 \sim 120$} \\
\hline \multirow{2}{*}{ Rotor Speed(krpm), $\omega$} & 15 & 21 & 25 \\
\hline & 28 & 50 & 100 \\
\hline
\end{tabular}

Fig.4 shows the predicted maximum bearing load capacity versus taper inlet height for different rotor speed under old model. The prediction results show that there is an optimal taper inlet height to maximize load capacity. Moreover, the optimal taper inlet height increases with the increasing rotor speed. The predicted maximum load capacity increases sharply with the increasing taper inlet height from 0 to the optimal taper inlet height. The predicted maximum load capacity decreases slowly with the increasing taper inlet height beyond the optimal taper inlet height. In exactly the same way, Fig.5 shows the predicted maximum bearing load capacity versus taper inlet height for different rotor speed under new model. Overall, the trend of the new model is consistent with the old model.

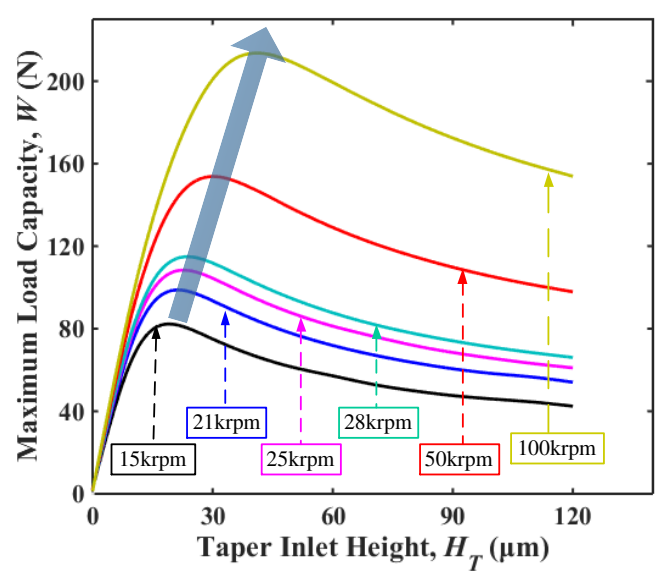

Fig. 4 The maximum load capacity versus taper inlet height under old model 


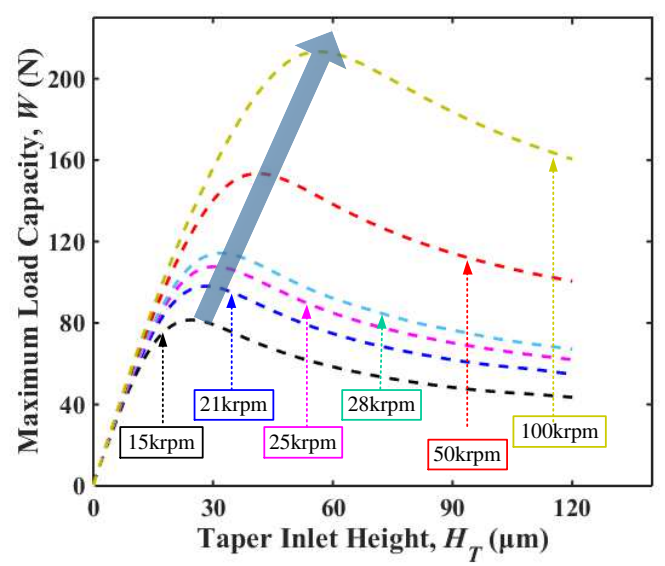

Fig. 5 The maximum load capacity versus taper inlet height under new model

Fig.6 is a combination of Fig.4 and Fig.5. It shows the comparison of simulation results between old model and new model. It should be noted that the optimal taper inlet height of new model is larger than old model (The whole curve shifted to the right) at the same rotor speed. The higher the rotor speed, the larger the maximum load capacity. This will lead to a larger amount of foil deformation, so the difference between the two models is more obvious at high speed. In particular, the predicted bearing load capacity of the two models is quite different before the optimal taper inlet height. The gap between the predicted load capacities by the two models gradually decrease and tend to be consistent when taper inlet height over the optimal value. Therefore, more attention should be paid to this difference when the optimal taper inlet height is chosen as the geometric parameter of bearing.

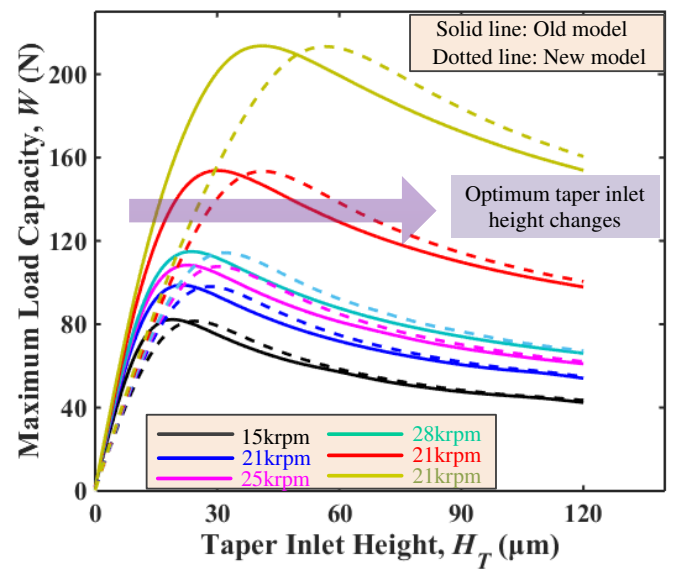

Fig. 6 The maximum load capacity versus taper inlet height under two models

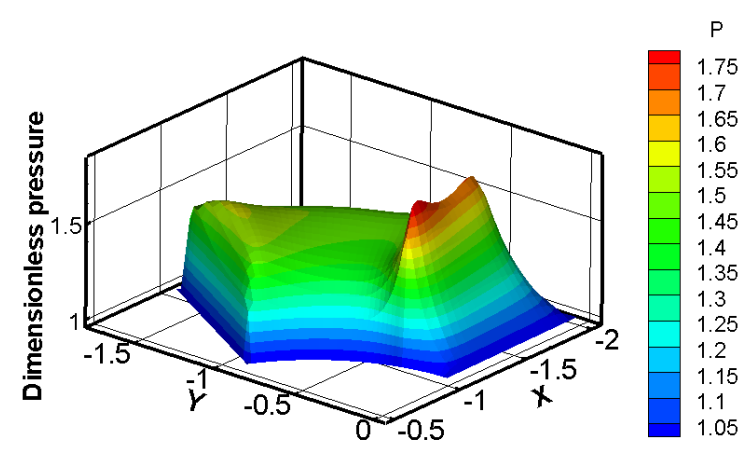

(a) Old model

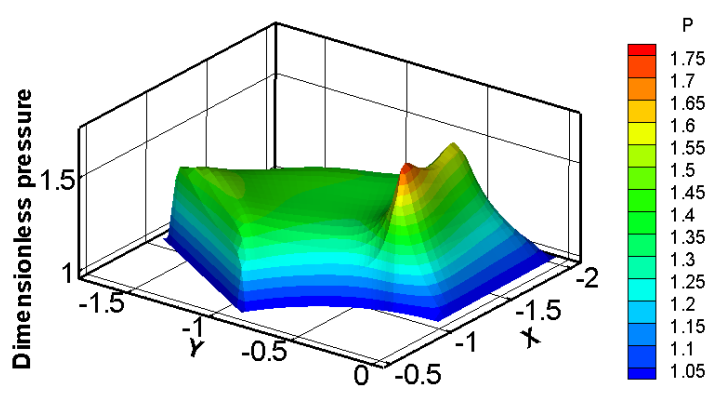

(b) New model

Fig. 7 Pressure distribution for taper inlet height $H_{T}=20 \mu \mathrm{m}$ and rotor speed $\omega=28 \mathrm{krpm}$

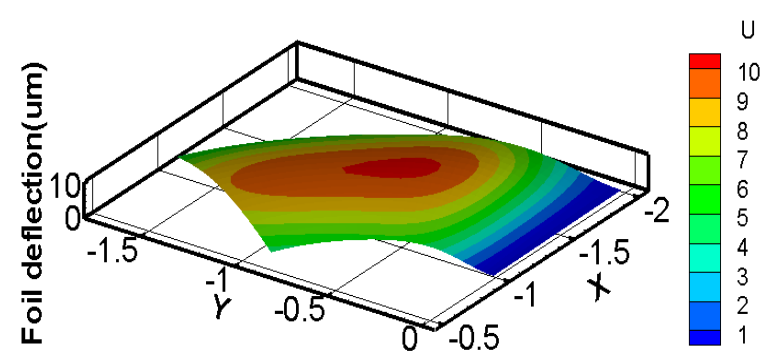

(a) Old model

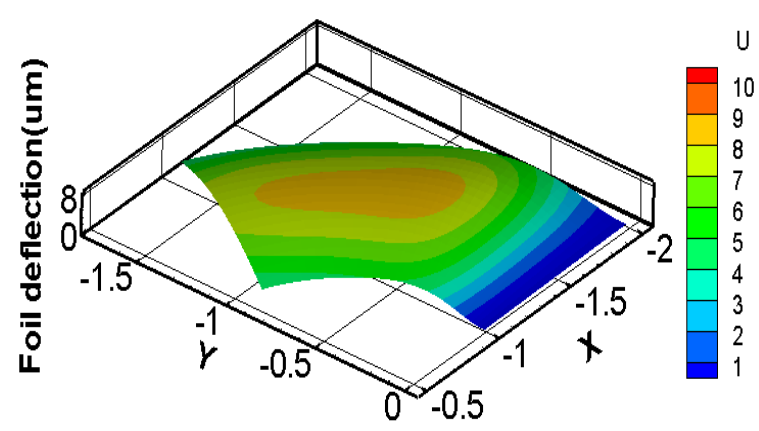

(b) New model

Fig. 8 Foil deflection distribution for taper inlet height $H_{T}=20 \mu \mathrm{m}$ and rotor speed $\omega=28 \mathrm{krpm}$ 


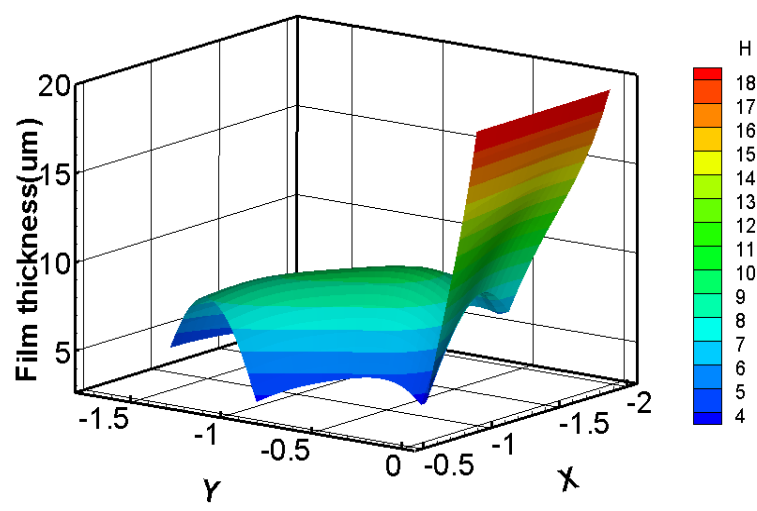

(a) Old model

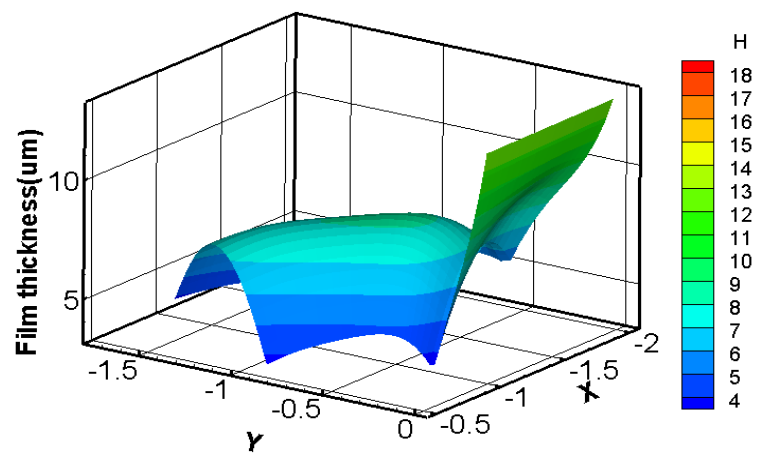

(b) New model

Fig. 9 Film thickness distribution for taper inlet height $H_{T}=20 \mu \mathrm{m}$ and rotor speed $\omega=28 \mathrm{krpm}$

Fig.7 shows the pressure distribution of a single pad for taper inlet height $H_{T}=20 \mu \mathrm{m}$ and rotor speed $\omega=28 \mathrm{krpm}$ under different models. Overall, the peak pressure simulated by new model is smaller than old model. This result also agrees with Fig.6. In addition, Fig. 8 shows the foil deflection distribution of a single pad for taper inlet height $H_{T}=20 \mu \mathrm{m}$ and rotor speed $\omega=28 \mathrm{krpm}$ under different models. The foil deformation is relatively small because the predicted maximum load capacity of the new model is relatively low. Fig.9 shows the film thickness distribution of a single pad for taper inlet height $H_{T}=20 \mu \mathrm{m}$ and rotor speed $\omega=28 \mathrm{krpm}$ under different models. The film thickness of new model is smaller than old model.

\section{Experiment and data analysis}

\subsection{Test rig introduction}

The physical diagram of the thrust bearing and test rig used in this paper is shown in the Fig.10, including the motor drive unit, the thrust bearing unit, the piston-loading unit and the relevant data acquiring unit.

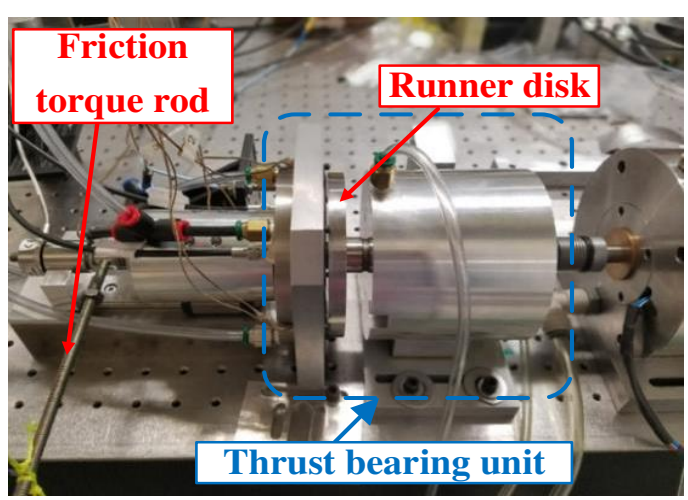

(a)

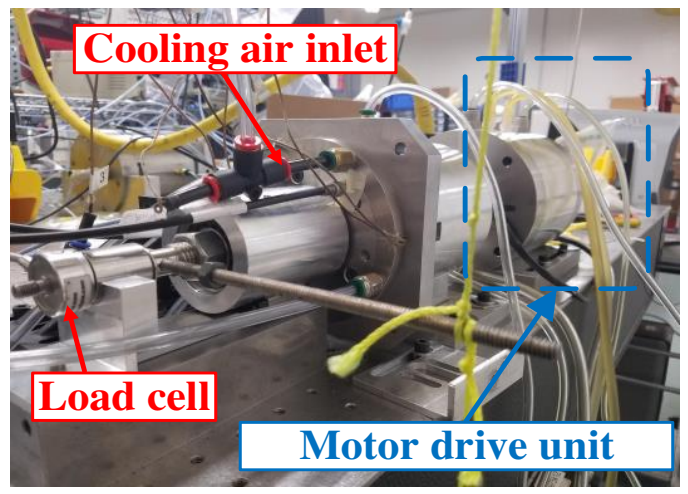

(b)

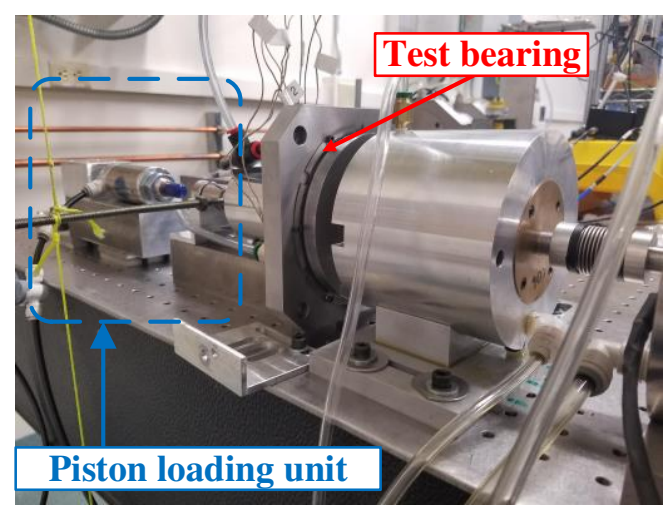

(c)

Fig. 10 The physical diagram of the thrust and test rig

The shaft is coupled to the high-speed motor via a coupling and the speed of motor can be adjusted arbitrarily by an inverter. The piston-loading unit includes piston shaft, cylinder and other connecting parts. The axial load is supplied and changed by adjust the piston-loading unit and load cell is used to response the size of load capacity. Otherwise, the force sensor (not shown in physical diagram) and the friction torque rod are used to measure the friction torque. Finally, the electrical signals collected by these sensors are collected into the computer through 
the relevant data acquiring unit.

The plane run-out of run disk is $2 \mu \mathrm{m}$ in the experiment. The first-order critical speed of shaft is $32,000 \mathrm{rpm}$ and the fundamental frequency vibration of the rotor is $6 \mu \mathrm{m}$ at $25,000 \mathrm{rpm}$, which meets the requirements of the experiment in principle.

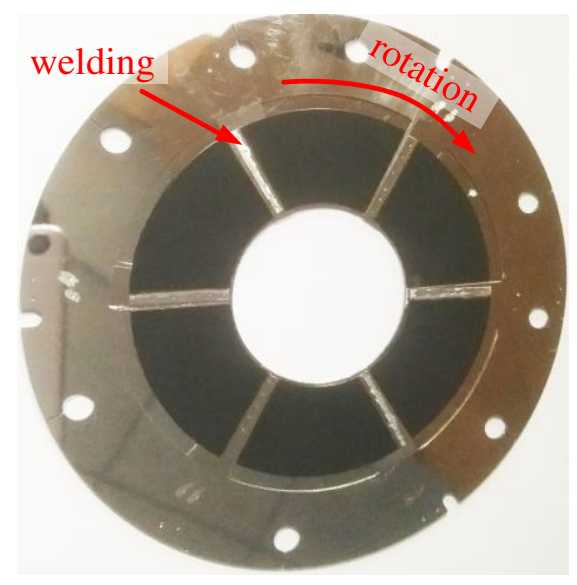

(a) Before test

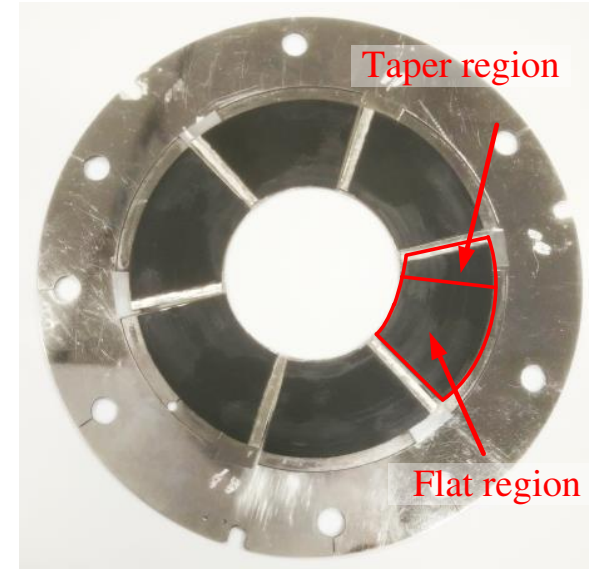

(b) After test

Fig. 11 Photos of the tested bearing

\subsection{Data analysis and discussion}

In this paper, three types of bearings with different taper inlet heights were tested at different rotor speeds. The relationship between friction torque and load capacity had been obtained by continually loading the tested bearing. Fig. 11 is photos of the air thrust foil bearing with taper inlet height $H_{T}=20 \mu \mathrm{m}$ before and after test. It can be seen that the wear of wear-resistant coating mainly occurs in the flat region. Table 2 lists the air thrust foil bearing parameters for test.

Table 2 Dimensions of thrust bearing for test

\begin{tabular}{lc}
\hline Foil bearing parameters & value \\
\hline Bearing inner radium(mm), $R_{I}$ & 18 \\
Bearing outer radium(mm), $R_{O}$ & 36 \\
Taper ratio, $b$ & 0.2564 \\
Pad angle(deg), $\beta$ & 58.5 \\
Pad number, $N$ & 6 \\
Stiffness of total bump foil (MN/m), $K$ & 11.58 \\
Top foil thickness (mm), $T_{\text {top }}$ & 0.2 \\
Young's modulus(GPa), $E$ & 800 \\
& Type1: 20 \\
Taper inlet height( $\mu \mathrm{m}), \quad H_{T}$ & Type2: 70 \\
& Type3: 114 \\
\hline Rotor Speed(krpm), $\omega$ & 15212528 \\
\hline
\end{tabular}

Fig. 12 shows the friction torque versus load capacity for taper inlet height $H_{T}=20 \mu \mathrm{m}, H_{T}=70 \mu \mathrm{m}$ and $H_{T}=114 \mu \mathrm{m}$ at different rotor speed. The top foil and runner disk had been touched when the friction torque rises sharply. At this time, the load capacity is considered to be the maximum bearing load capacity. The maximum load capacity corresponding to $15 \mathrm{rpm}, 21 \mathrm{rpm}, 25 \mathrm{rpm}$ and $28 \mathrm{rpm}$ is $60 \mathrm{~N}$, $73 \mathrm{~N}, 78 \mathrm{~N}$ and $100 \mathrm{~N}$ respectively when taper inlet height $H_{T}=20 \mu \mathrm{m}$. The maximum load capacity corresponding to $15 \mathrm{rpm}, 21 \mathrm{rpm}, 25 \mathrm{rpm}$ and $28 \mathrm{rpm}$ is $46 \mathrm{~N}, 60 \mathrm{~N}, 72 \mathrm{~N}$ and $84 \mathrm{~N}$ respectively when taper inlet height $H_{T}=70 \mu \mathrm{m}$. The maximum load capacity corresponding to $15 \mathrm{rpm}, 21 \mathrm{rpm}$, $25 \mathrm{rpm}$ and $28 \mathrm{rpm}$ is $35 \mathrm{~N}, 53 \mathrm{~N}, 69 \mathrm{~N}$ and $82 \mathrm{~N}$ respectively when taper inlet height $H_{T}=114 \mu \mathrm{m}$. It can be seen that the maximum load capacity increases with increasing rotor speed. The air thrust foil bearing with taper inlet height of $20 \mu \mathrm{m}$ has better performance. 


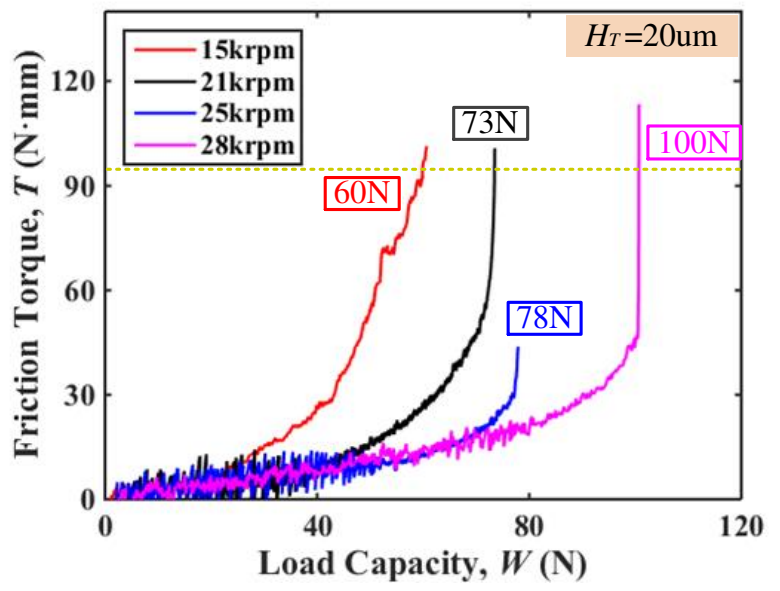

(a) $H_{T}=20 \mu \mathrm{m}$

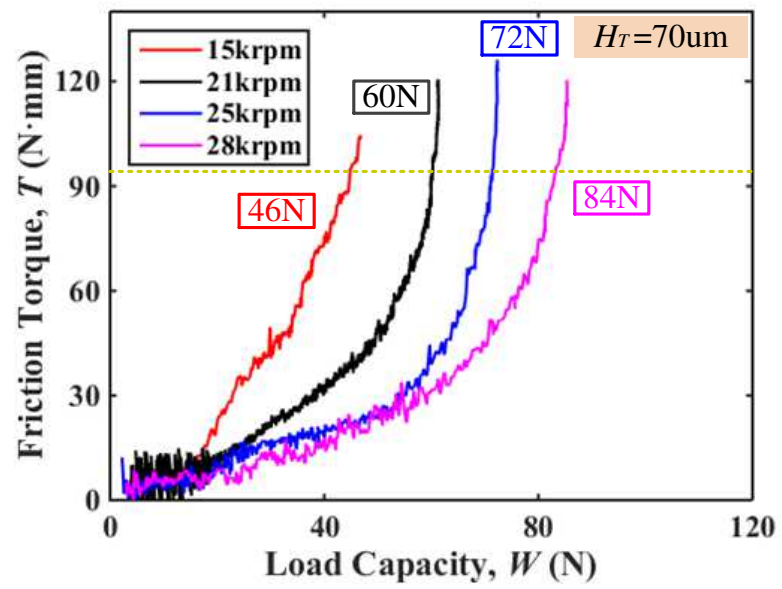

(b) $H_{T}=70 \mu \mathrm{m}$

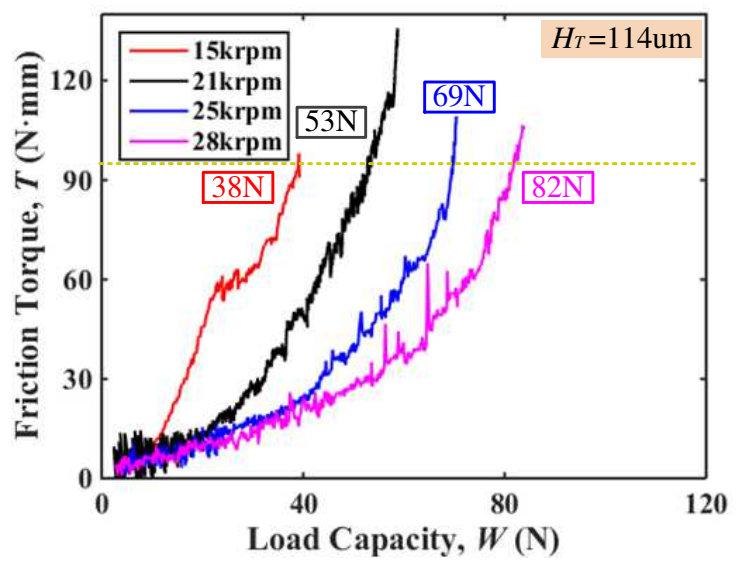

(c) $H_{T}=114 \mu \mathrm{m}$

Fig. 12 Friction torque versus load capacity for taper inlet height $H_{T}=20 \mu \mathrm{m}, H_{T}=70 \mu \mathrm{m}$ and $H_{T}=114 \mu \mathrm{m}$ at different rotor speed

Fig.13 shows the maximum load capacity versus taper inlet height for different rotor speed under two models and test. It can be seen that the predicted load capacity of the new model are more agree with the test results than the old model when taper inlet height $H_{T}=20 \mu \mathrm{m}$. The higher the rotor speed, the better the performance of the new model will be. There isn't much difference between the two models when taper inlet height $H_{T}$ over the optimal taper inlet height. The tested load capacity will be much lower than the theoretical value if the optimal taper inlet height is selected according to the old model. Accordingly, greater attention should be focused on the characteristics of real-time variable taper inlet height when designing thrust bearing.

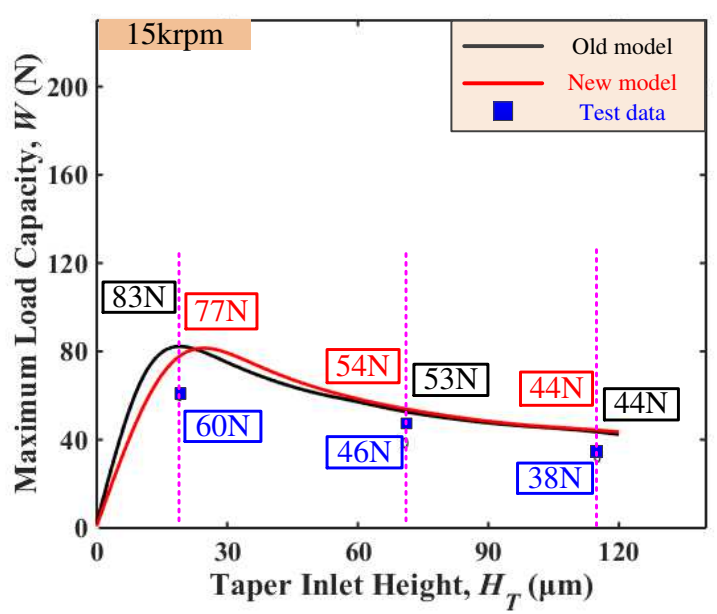

(a) $\omega=15 \mathrm{krpm}$

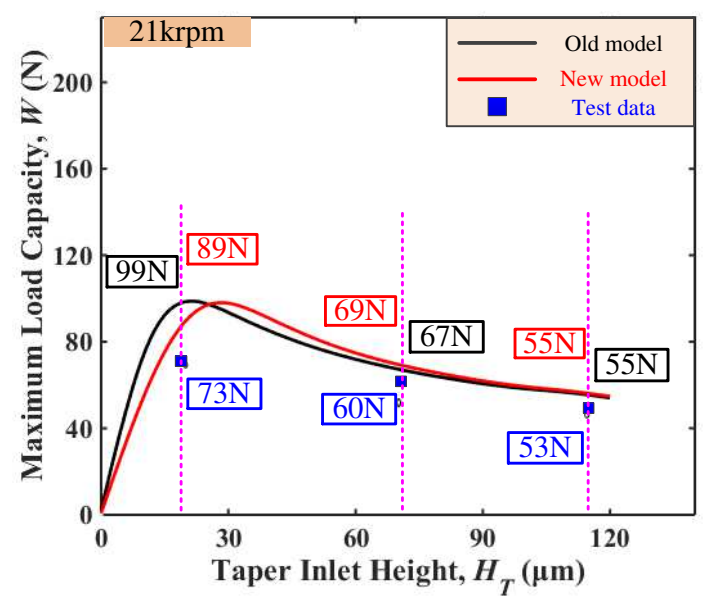

(b) $\omega=21 \mathrm{krpm}$ 


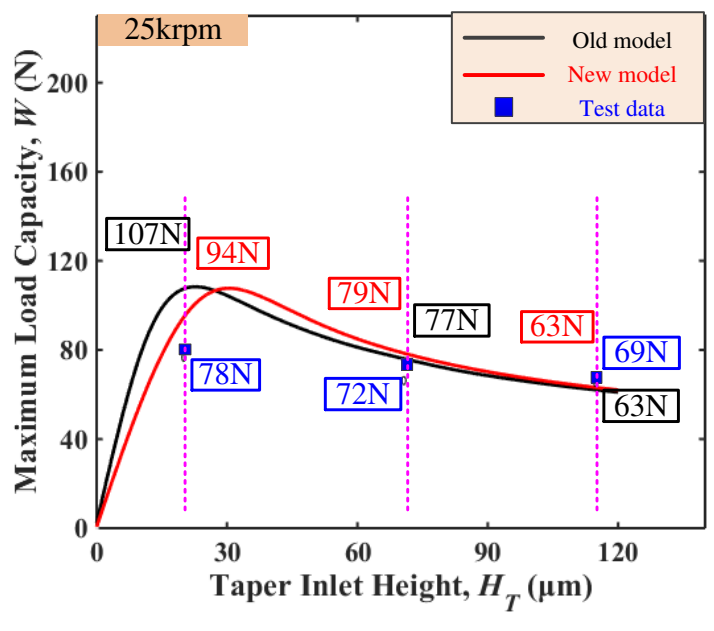

(c) $\omega=25 \mathrm{krpm}$

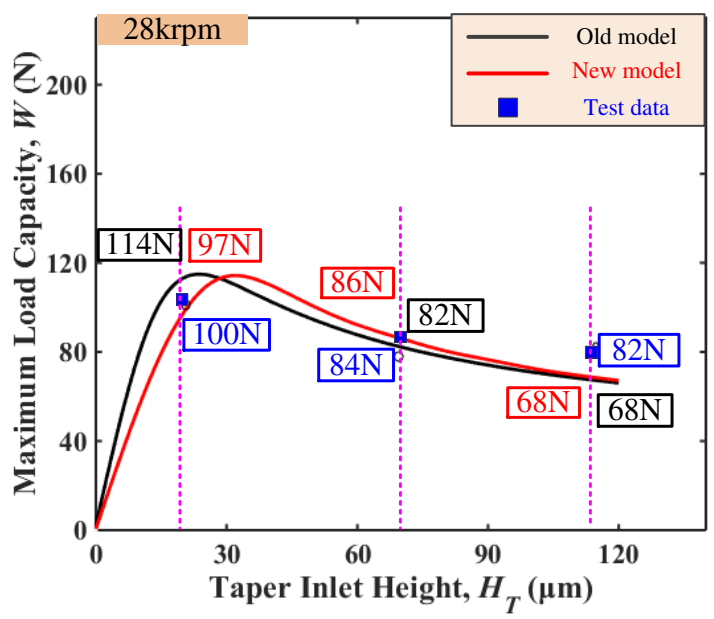

(d) $\omega=28 \mathrm{krpm}$

Fig. 13 Maximum load capacity versus taper inlet height for different rotor speed under two models and test

\section{Conclusion}

In this paper, a computational model for adjusting the taper inlet height of the bearing in real-time has been proposed. The improved calculation model can adjust the taper inlet height in real-time according to the foil deflection. In the iteration process (code), initial taper inlet height $H_{T}$ had been replaced by actual taper inlet height $H_{\text {actual }}$ before calculating the film thickness distribution.

The predicted maximum load capacity versus taper inlet height for different rotor speed had been simulated. The prediction results show that there is an optimal taper inlet height to maximize load capacity, and the optimal taper inlet height of new model is larger than old model at the same rotor speed. Moreover, the predicted bearing load capacity of the two models is quite different before the optimal taper inlet height.

Three types of air thrust foil bearing with different taper inlet height had been tested. The maximum bearing load capacity of different types of bearings at different rotor speeds had been obtained. The test results had been compared with the simulation results. It can be found that the new model performs better than the old model when the taper inlet height $H_{T}=20 \mu \mathrm{m}$ (less than the optimal taper inlet height). Moreover, the higher the rotor speed, the better the performance of the new model will be. The predicted results of the two models are almost the same when the taper inlet height far beyond the optimal value. Therefore, more attention should be focused on the characteristics of real-time variable taper inlet height when the taper inlet height of the bearing is no more than the optimum value.

\section{Declaration}

\section{Funding}

Supported by National Natural Science Foundation of China (NSFC) (Grant No. 11702050) and the 64th batch of China Post-doctoral Science Foundation (2018M641690).

\section{Availability of data and materials}

The datasets supporting the conclusions of this article are included within the article.

\section{Authors' contributions}

The author' contributions are as follows: Fangcheng Xu was in charge of the whole trial; Liukai Hou wrote the manuscript; Bin $\mathrm{Wu}$ assisted with sampling and laboratory analyses; Zeda Dong and Yongliang wang did bearing experiments.

\section{Competing interests}

The authors declare no competing financial interests.

\section{Consent for publication}

Not applicable

Ethics approval and consent to participate 


\section{Not applicable}

\section{Nomenclature}

\begin{tabular}{|c|c|}
\hline$b$ & Taper tatio \\
\hline C & Bearing nominal clearance \\
\hline$h$ & Film thickness \\
\hline $\bar{h}$ & Nondimensionalized film thickness \\
\hline$g$ & Taper height \\
\hline $\bar{g}$ & Nondimensionalized Taper height \\
\hline$H_{T}$ & Initial taper inlet height \\
\hline$H_{\text {actual }}$ & Actual taper inlet height \\
\hline$H_{d e}$ & Foil deflection \\
\hline$T_{\text {top }}$ & Top foil thickness \\
\hline$H_{\text {bump }}$ & Bump foil thickness \\
\hline$p$ & Film pressure \\
\hline $\bar{p}$ & Nondimensionalized film pressure \\
\hline$p_{a}$ & Ambient pressure \\
\hline$r$ & radial location \\
\hline $\bar{r}$ & Nondimensionalized radial location \\
\hline$R_{O}$ & Bearing outer radium \\
\hline$R_{I}$ & Bearing inner radium \\
\hline$T$ & Bearing friction torque \\
\hline$w$ & Foil deflection \\
\hline $\bar{w}$ & Nondimensionalized foil deflection \\
\hline$W$ & Bearing load capacity \\
\hline$H_{m}$ & Minimum film thickness \\
\hline$N$ & Pad number \\
\hline$\Lambda$ & Bearing number \\
\hline$\mu$ & Viscosity of air \\
\hline$\omega$ & Rotor speed of runner disk \\
\hline$\beta$ & Pad angle \\
\hline$v$ & Poisson's ratio \\
\hline$\theta$ & $\mathrm{C}$ \\
\hline
\end{tabular}

\section{References}

[1] Agrawal, G. L. 1997. "Foil air/gas bearing technology — an overview." (78682), V001T004A006.

[2] Heshmat, H., Walton, I. I. J. F., Corte, C. D., and Valco, M. 2000. "Oil-free turbocharger demonstration paves way to gas turbine engine applications." (78545), V001T004A008.

[3] Choe, B. S., Kim, T. H., Kim, C. H., and Lee, Y. B. 2015. "Rotordynamic behavior of $225 \mathrm{kw}(300 \mathrm{hp})$ class pms motor-generator system supported by gas foil bearings." Journal of Engineering for Gas Turbines and Power-Transactions of the Asme, 137(9).

[4] Fu, G., Untaroiu, A., and Swanson, E. 2018. "Effect of foil geometry on the static performance of thrust foil bearings." Journal of Engineering for Gas Turbines and Power-Transactions of the Asme, 140(8).

[5] Xu, F., Kim, D., and Zamanian Yazdi, B. 2016. "Theoretical study of top foil sagging effect on the performance of air thrust foil bearing." (49842), V07BT31A013.

[6] Heshmat, H., Walowit, J. A., and Pinkus, O. 1983. "Analysis of gas lubricated compliant thrust-bearings." Journal of Lubrication Technology-Transactions of the Asme, 105(4), 638-646.

[7] Kim, T. H., Lee, Y.-B., Kim, T. Y., and Jeong, K. H. 2012. "Rotordynamic performance of an oil-free turbo blower focusing on load capacity of gas foil thrust bearings." Journal of Engineering for Gas Turbines and Power-Transactions of the Asme, 134(2).

[8] Ku, C.-P. R., and Heshmat, H. 1992. "Compliant foil bearing structural stiffness analysis: Part $\mathrm{i}$ - theoretical model including strip and variable bump foil geometry." Journal of Tribology, 114(2), 394-400

[9] Heshmat, H., Walowit, J. A., and Pinkus, O. 1983. "Analysis of gas-lubricated foil journal bearings." Journal of Tribology, 105(4), 647-655.

[10] Dellacorte, C., and Valco, M. J. 2000. "Load capacity estimation of foil air journal bearings for oil-free turbomachinery applications." Tribology Transactions, 43(4), 795-801.

[11] Dykas, B., Bruckner, R., DellaCorte, C., Edmonds, B., and Prahl, J. 2009. "Design, fabrication, and performance of foil gas thrust bearings for microturbomachinery applications." Journal of Engineering for Gas Turbines and Power-Transactions of the Asme, 131(1).

[12] Zhou, Q., Hou, Y., and Chen, C. 2009. "Dynamic stability experiments of compliant foil thrust bearing with viscoelastic support." Tribology International, 42(5), 662-665.

[13] Lee, D., and Kim, D. 2011. "Design and performance prediction of hybrid air foil thrust bearings." Journal of Engineering for Gas Turbines and Power-Transactions of the Asme, 133(4).

[14] Balducchi, F., Arghir, M., Gauthier, R., and Renard, E. 2013. "Experimental analysis of the start-up torque of a mildly loaded foil thrust bearing." Journal of Tribology-Transactions of the Asme, 135(3).

[15] Gad, A. M., and Kaneko, S. 2014. "A new structural stiffness model for bump-type foil bearings: Application to generation ii gas lubricated foil thrust bearing." Journal of 
Tribology-Transactions of the Asme, 136(4).

[16] Fu, G., and Untaroiu, A. 2018. "The influence of surface patterning on the thermal properties of textured thrust bearings." Journal of Tribology-Transactions of the Asme, 140(6).

[17] Qin, K., Jahn, I. H., and Jacobs, P. A. 2017. "Effect of operating conditions on the elastohydrodynamic performance of foil thrust bearings for supercritical co2 cycles." Journal of Engineering for Gas Turbines and Power-Transactions of the Asme, 139(4).

[18] LaTray, N. T., and Kim, D. 2018. "A high speed test rig capable of running at $190,000 \mathrm{rpm}$ to characterize gas foil thrust bearings." (51142), V07BT34A043.

[19] Ku, C. P. R. 1994. "Dynamic structural-properties of compliant foil thrust-bearings - comparison between experimental and theoretical results." Journal of Tribology-Transactions of the Asme, 116(1), 70-75.

[20] Iordanoff, I. 1999. "Analysis of an aerodynamic compliant foil thrust bearing: Method for a rapid design." Journal of Tribology-Transactions of the Asme, 121(4), 816-822.

[21] Heshmat, C. A., Xu, D. S., and Heshmat, H. 2000. "Analysis of gas lubricated foil thrust bearings using coupled finite element and finite difference methods." Journal of Tribology-Transactions of the Asme, 122(1), 199-204.

[22] Kim, T. H., Park, M., and Lee, T. W. 2017. "Design optimization of gas foil thrust bearings for maximum load capacity." Journal of Tribology-Transactions of the Asme, 139(3).

[23] Lehn, A., Mahner, M., and Schweizer, B. 2016. "Elasto-gasdynamic modeling of air foil thrust bearings with a two-dimensional shell model for top and bump foil." Tribology International, 100, 48-59.

[24] Park, D.-J., Kim, C.-H., Jang, G.-H., and Lee, Y.-B. 2008. "Theoretical considerations of static and dynamic characteristics of air foil thrust bearing with tilt and slip flow." Tribology International, 41(4), 282-295.

[25] Lee, Y.-B., Kim, T. Y., Kim, C. H., and Kim, T. H. 2011. "Thrust bump air foil bearings with variable axial load: Theoretical predictions and experiments." Tribology Transactions, 54(6), 902-910.

[26] San Andres, L., Ryu, K., and Diemer, P. 2015. "Prediction of gas thrust foil bearing performance for oil-free automotive turbochargers." Journal of Engineering for Gas Turbines and Power-Transactions of the Asme, 137(3).

[27] Conboy, T. M. 2013. "Real-gas effects in foil thrust bearings operating in the turbulent regime." Journal of Tribology-Transactions of the Asme, 135(3).

\section{Biographical notes}

Fang-cheng Xu, born in 1985, is now an associate professor of School of Control Science and Engineering, Dalian University of Technology and DUT Artificial Intelligence Institute, Dalian, China. His research interests include gas foil bearing, foil seal, rotor dynamics and oil-free turbomachinery.
Tel: +86-13610847587; E-mail: fcxu@dlut.edu.cn

Liu-kai Hou, born in 1996, is now an engineer of Beijing Aerospace Propulsion Institute, Beijing, China. He received his master degree from Dalian University of Technology, China, in 2020. His research interests include gas foil bearing and rotor dynamics.

Bin Wu, born in 1965, is now a chief engineer of Suzhou Dongling Vibration Test Instrument Co., Ltd, Suzhou, China. His research interests include noise and vibration control.

Ze-da Dong, born in 1997, is now a master student of School of Control Science and Engineering, Dalian University of Technology, China. He received his bachelor degree from Dalian Maritime University, China, in 2019. His research interests include gas foil bearing and rotor dynamics.

Yong-liang Wang, born in 1983, is now an associate professor of Naval Architecture and Ocean Engineering College, Dalian Maritime University, China. His research interests include gas foil bearing and rotor dynamics. 
Figures

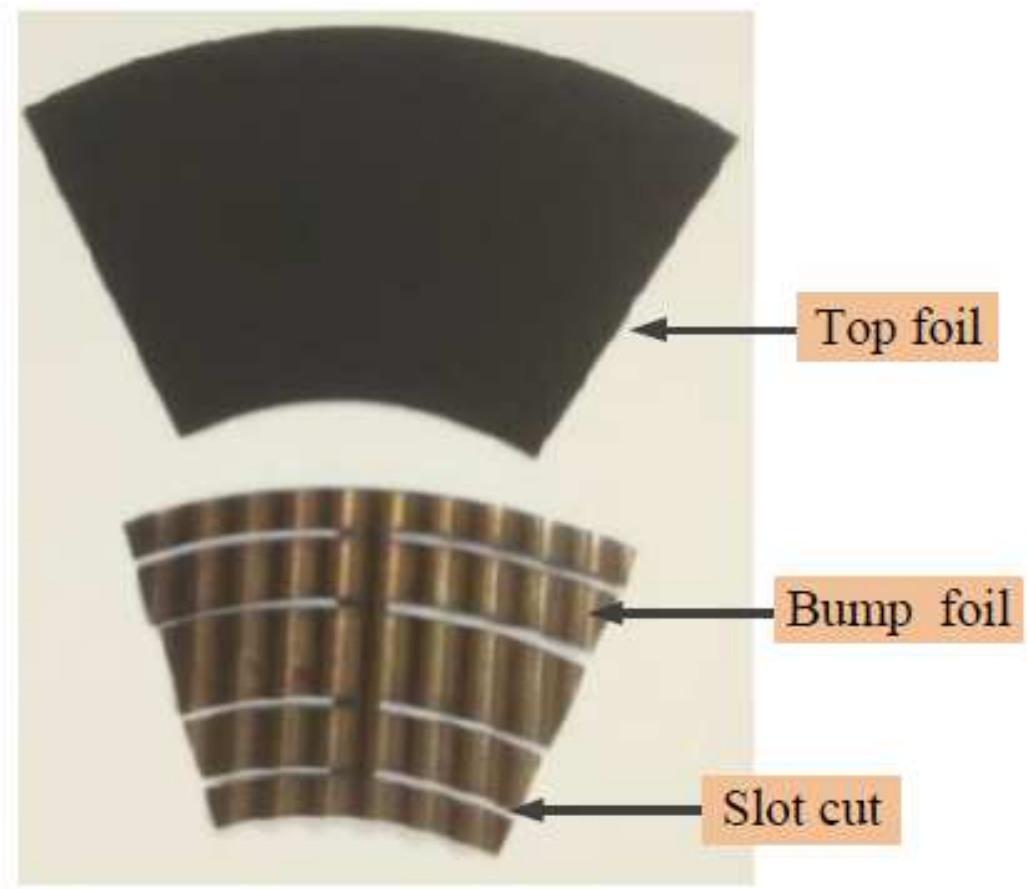

(a)

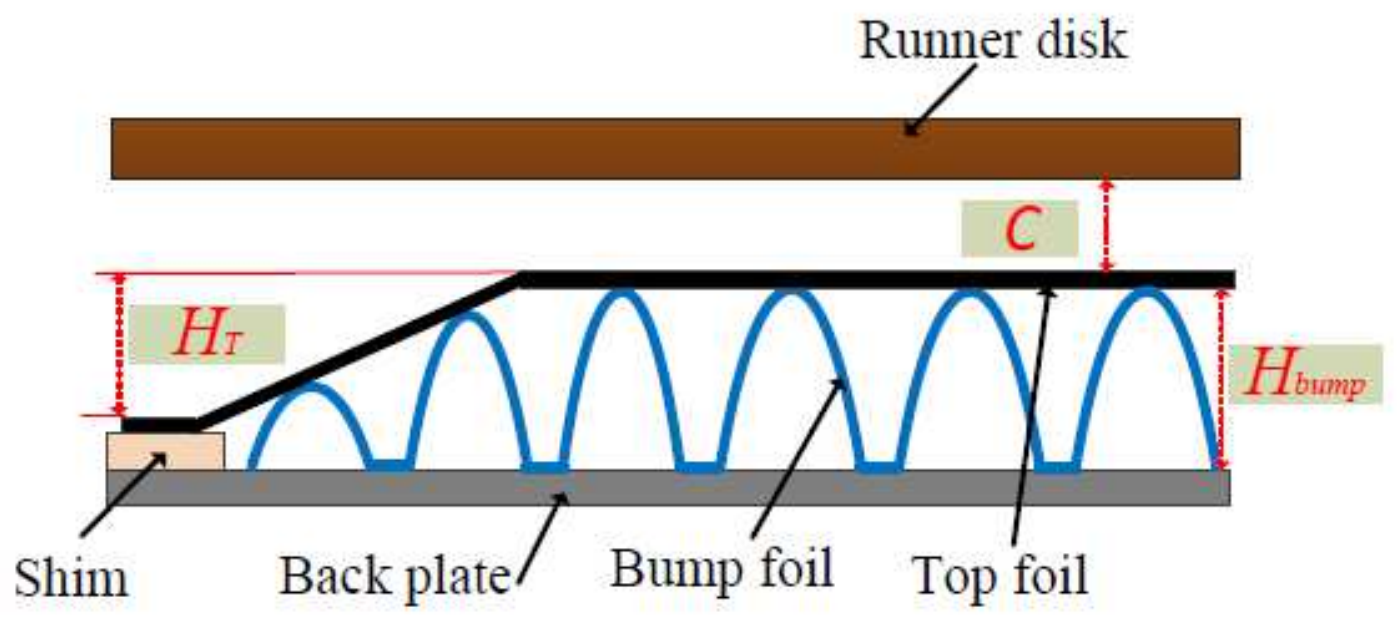

(b)

Figure 1

Structure design of air thrust foil bearing 
Runner disk
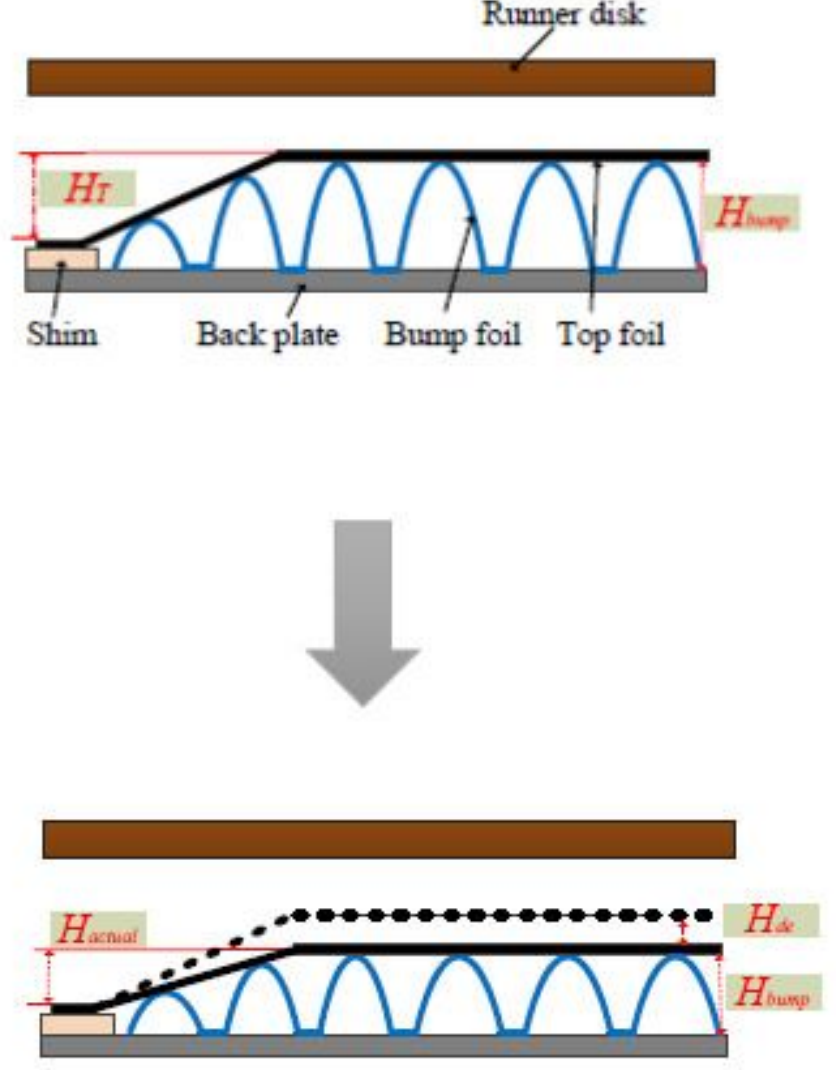

Figure 2

Schematic Diagram of the model 


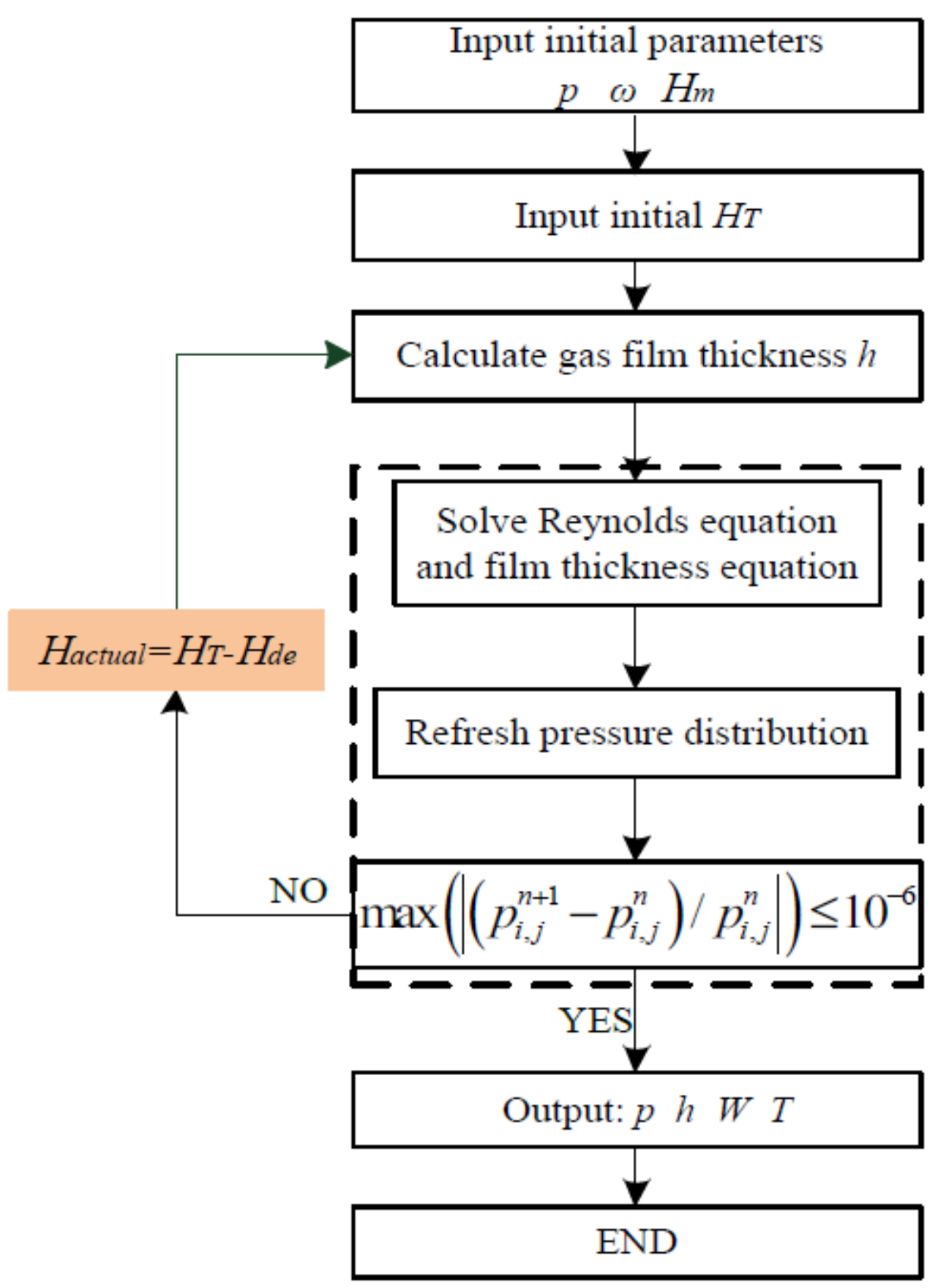

Figure 3

Code flow chart 


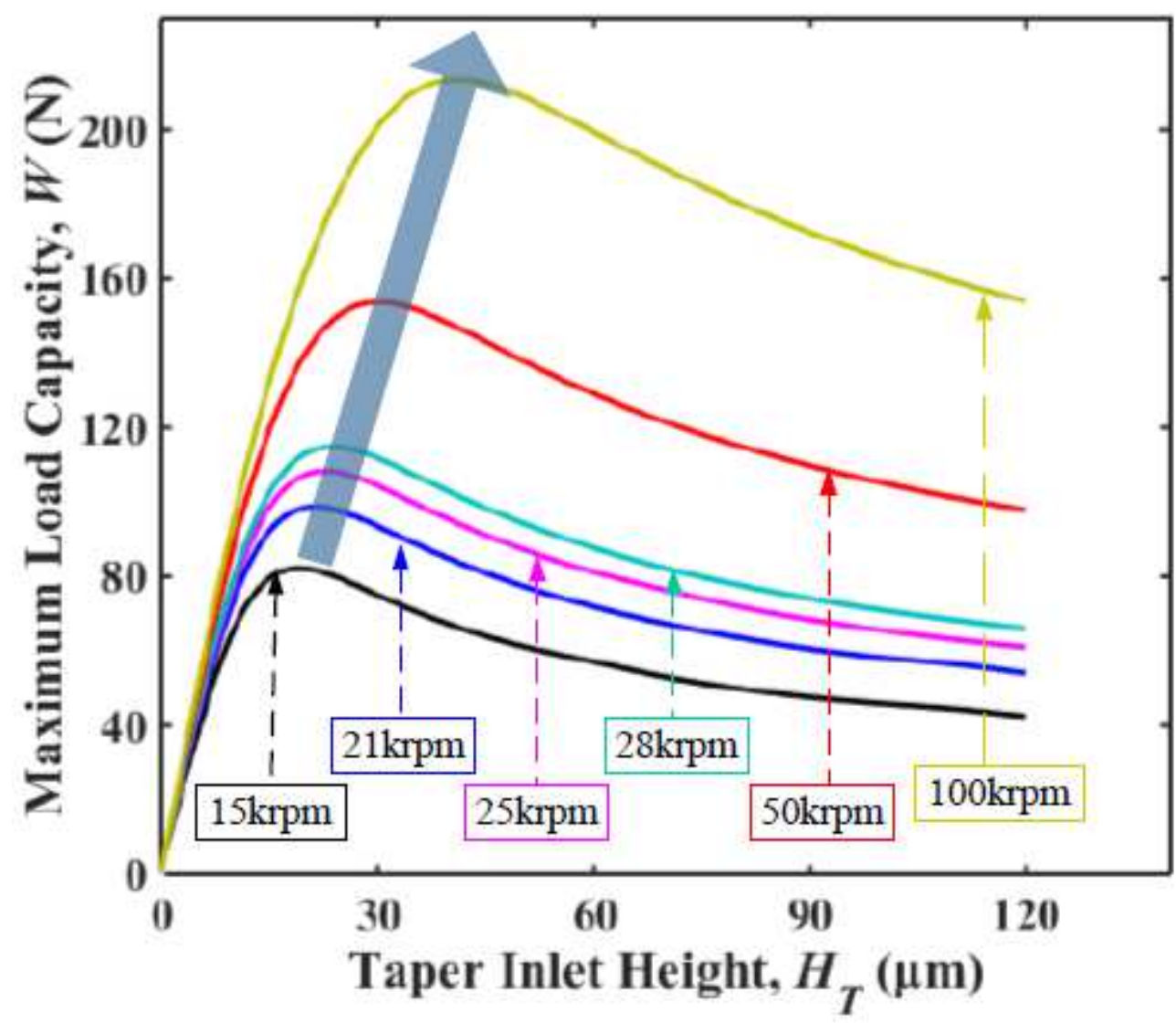

Figure 4

The maximum load capacity versus taper inlet height under old model 


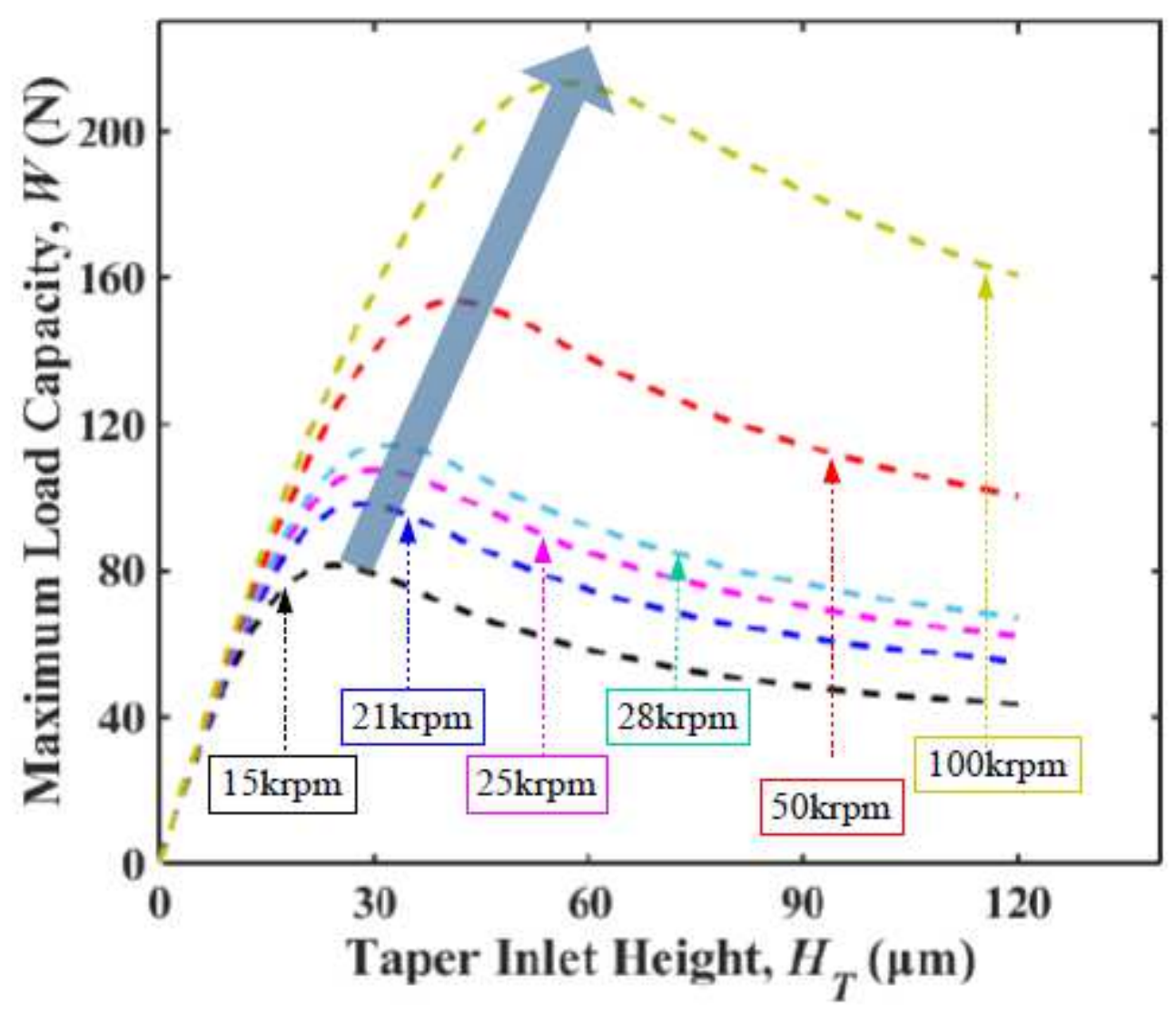

Figure 5

The maximum load capacity versus taper inlet height under new model 


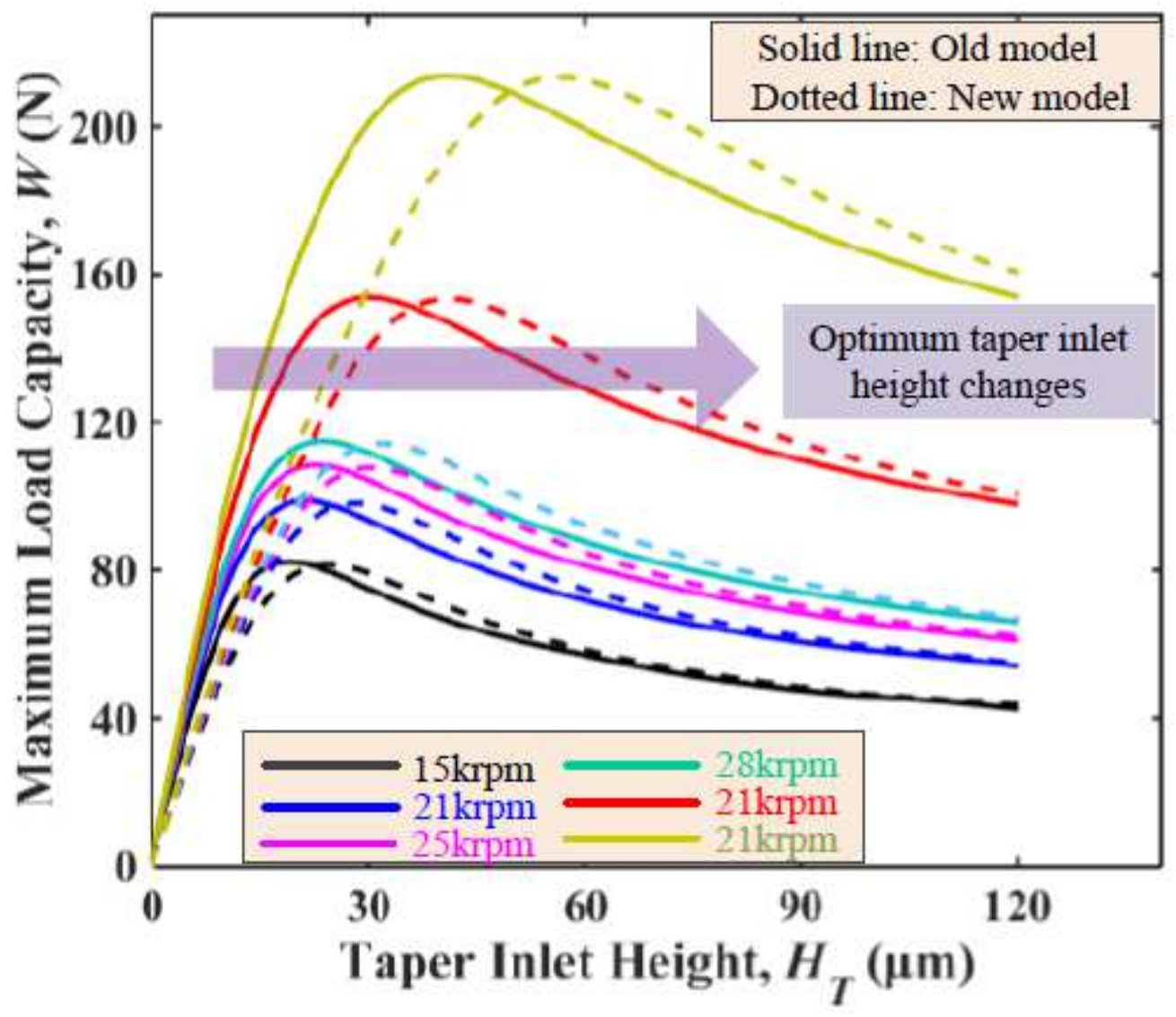

Figure 6

The maximum load capacity versus taper inlet height under two models 


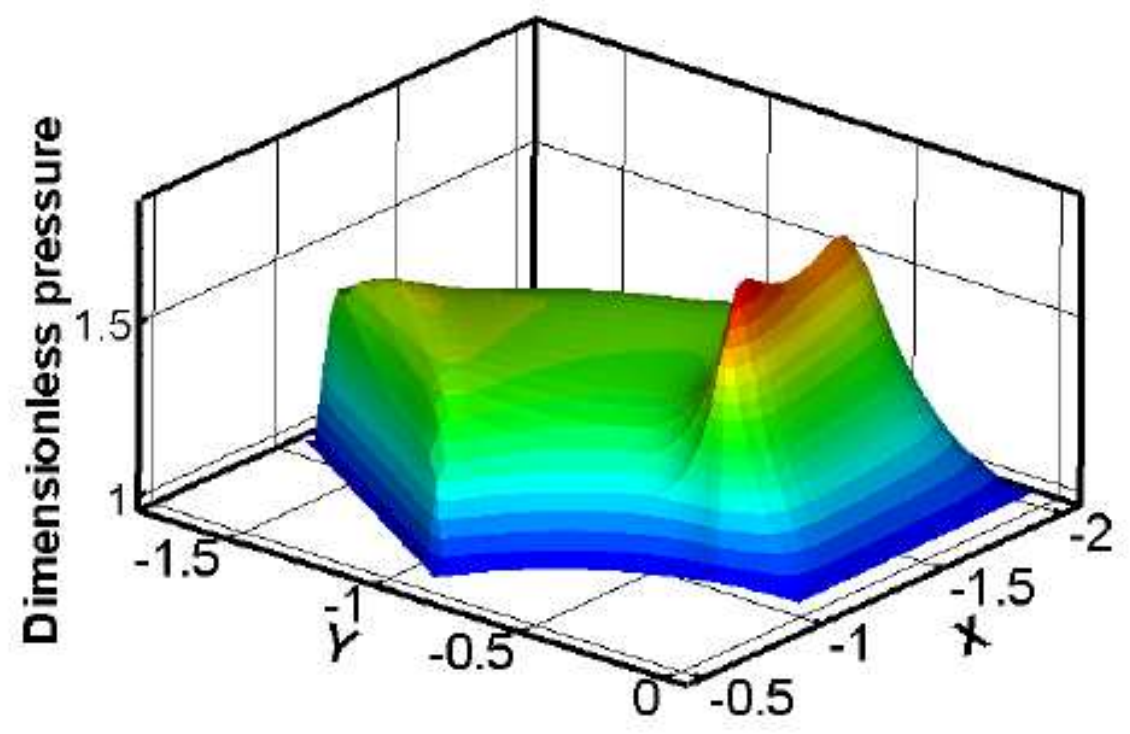

1.75

1.7

1.65

1.6

1.55

1.5

1.45

1.4

1.35

1.3

1.25

1.2

1.15

1.1

1.05

(a) Old model
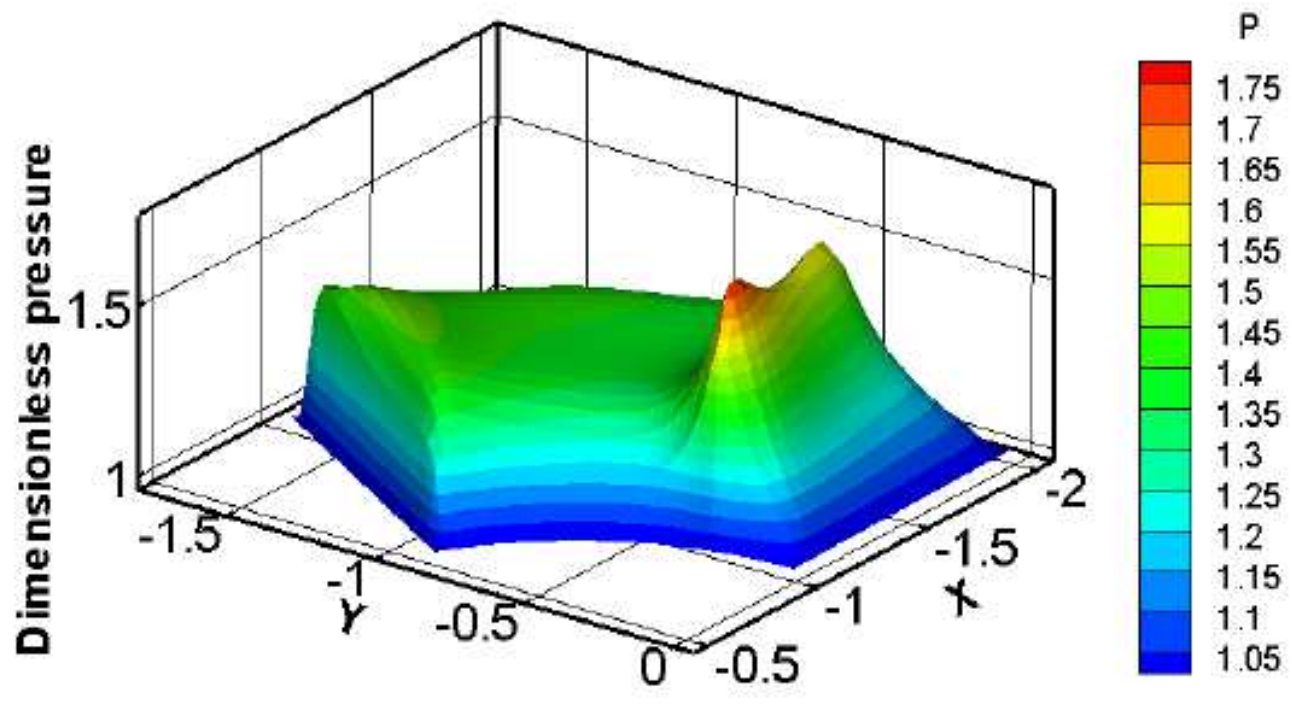

(b) New model

Figure 7

Pressure distribution for taper inlet height $\mathrm{HT}=20 \mu \mathrm{m}$ and rotor speed $\omega=28 \mathrm{krpm}$ 


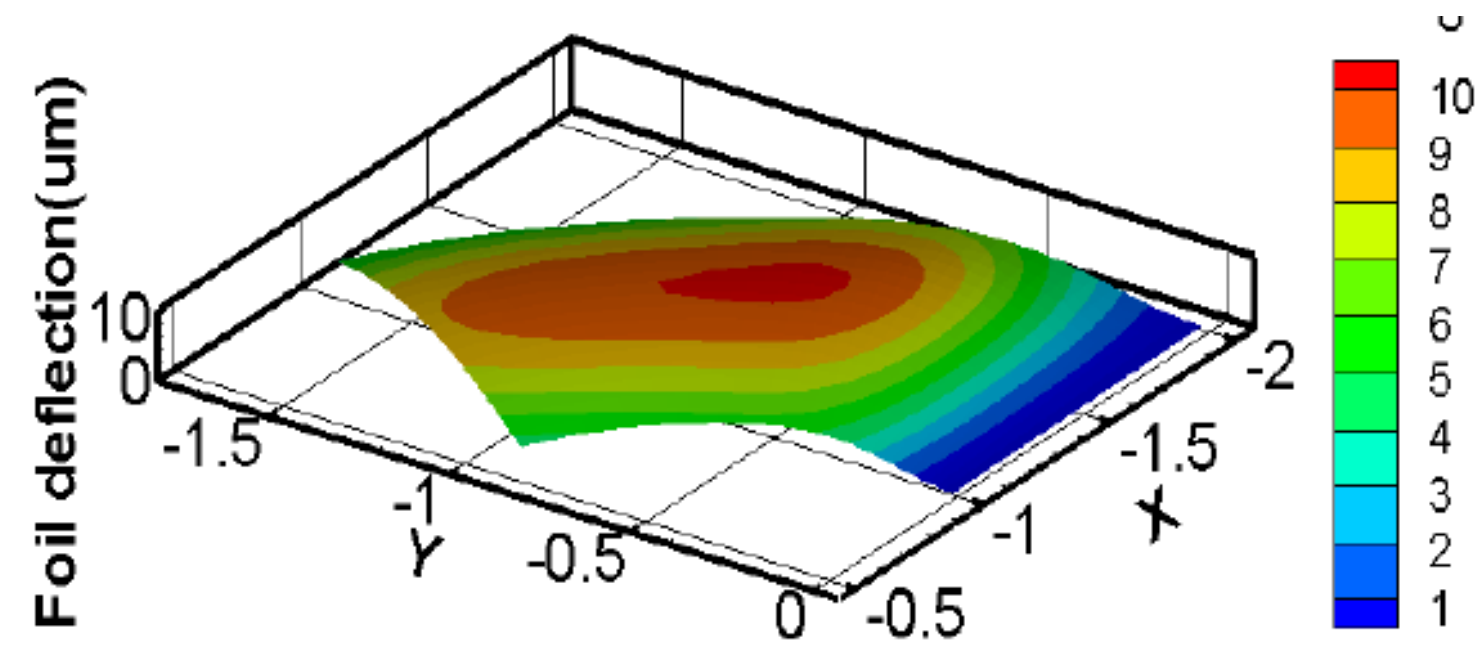

(a) Old model

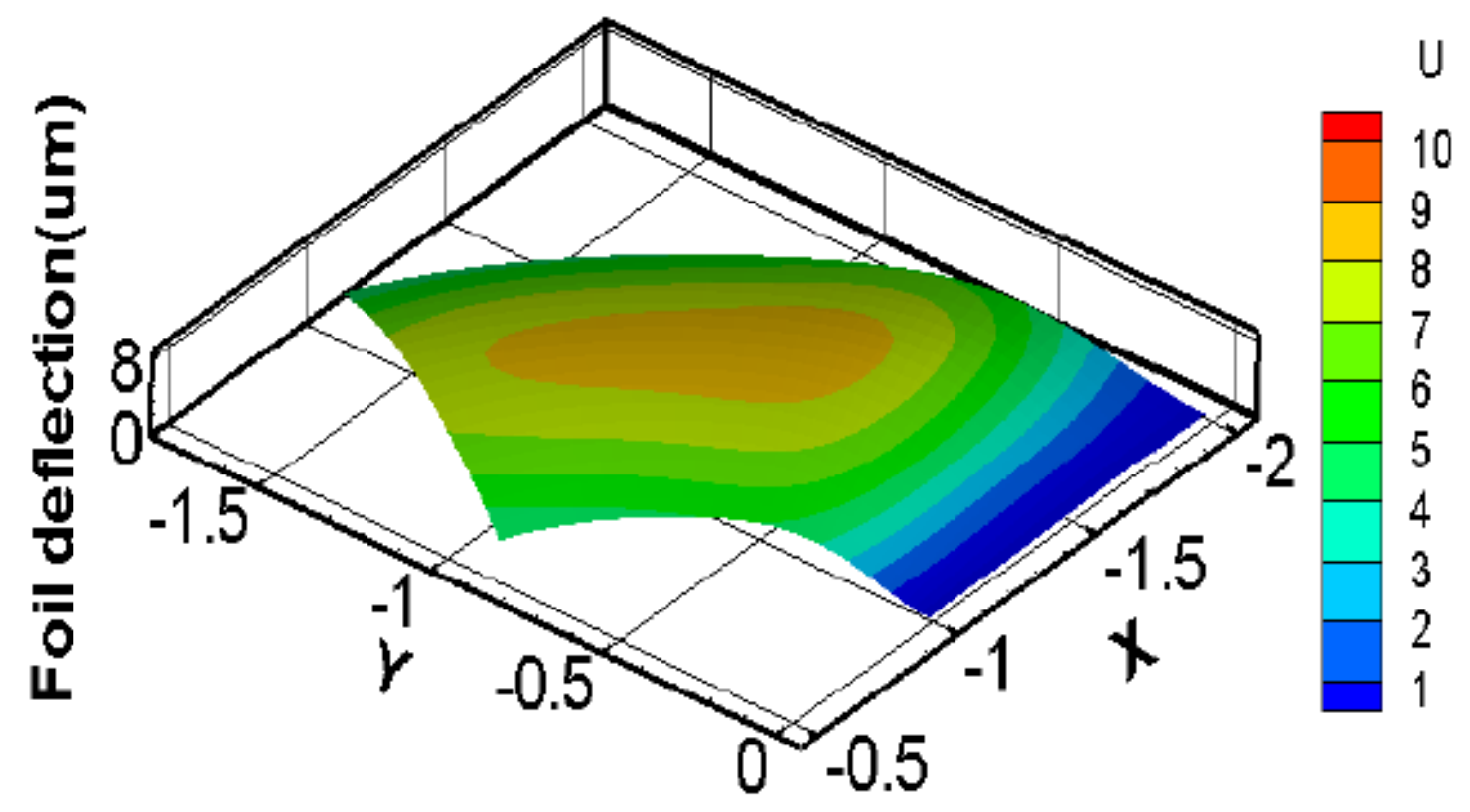

(b) New model

Figure 8

Foil deflection distribution for taper inlet height $\mathrm{HT}=20 \mu \mathrm{m}$ and rotor speed $\omega=28 \mathrm{krpm}$ 


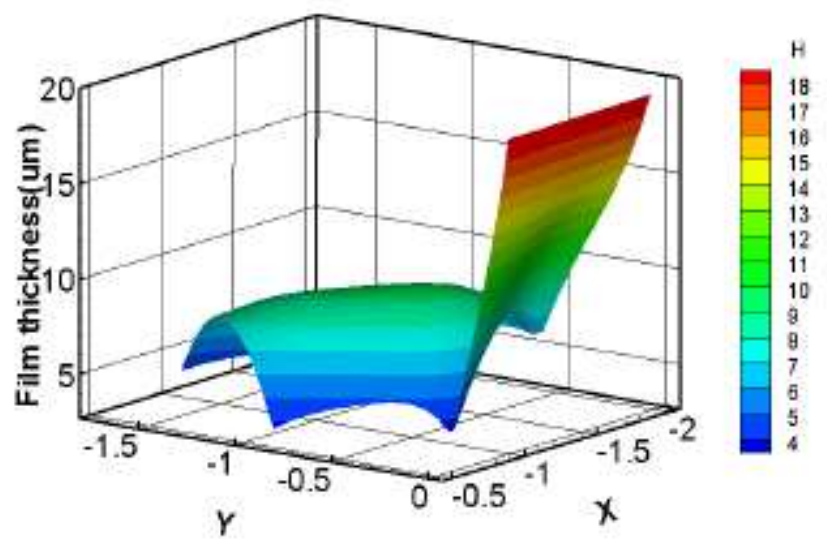

(a) Old model

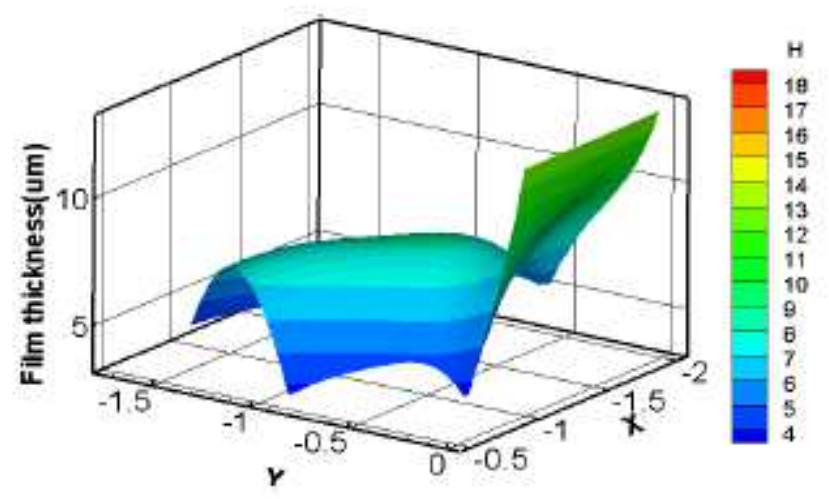

(b) New model

Figure 9

Film thickness distribution for taper inlet height $\mathrm{HT}=20 \mu \mathrm{m}$ and rotor speed $\omega=28 \mathrm{krpm}$ 


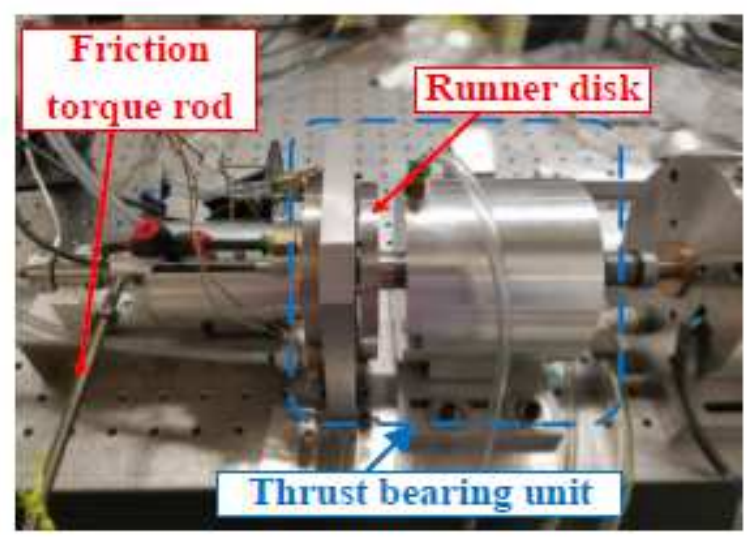

(a)

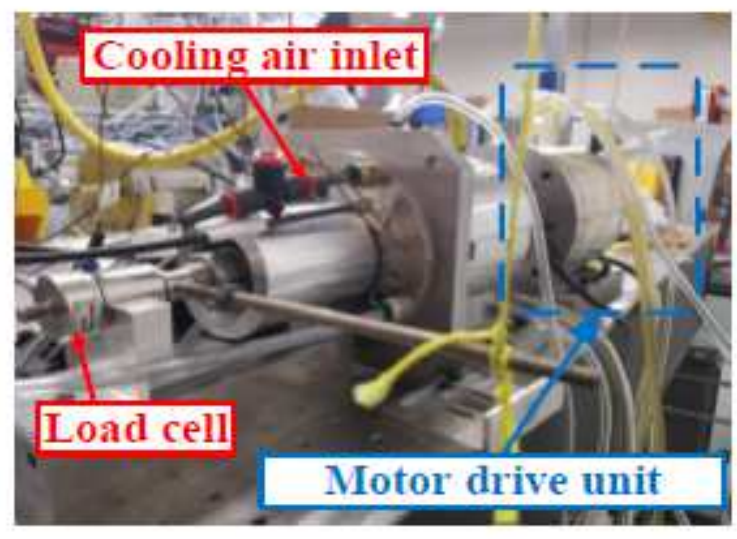

(b)

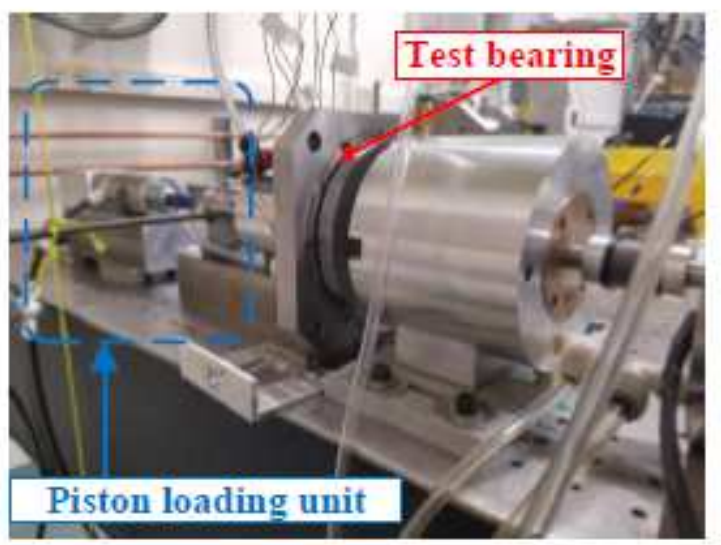

(c)

\section{Figure 10}

The physical diagram of the thrust and test rig 


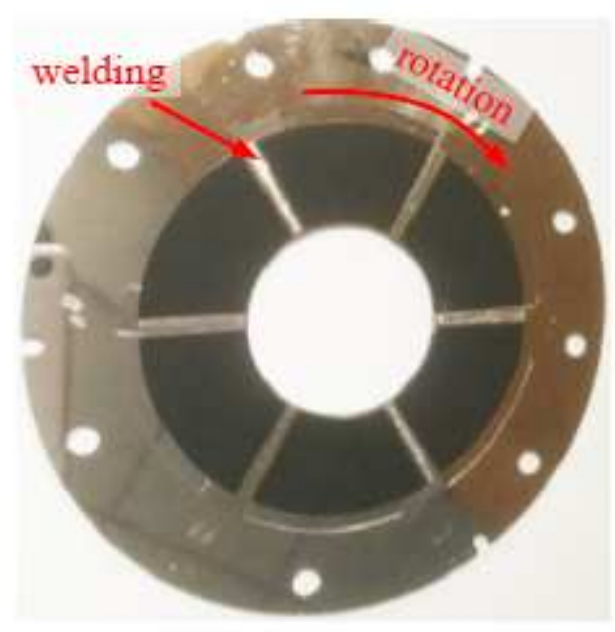

(a) Before test

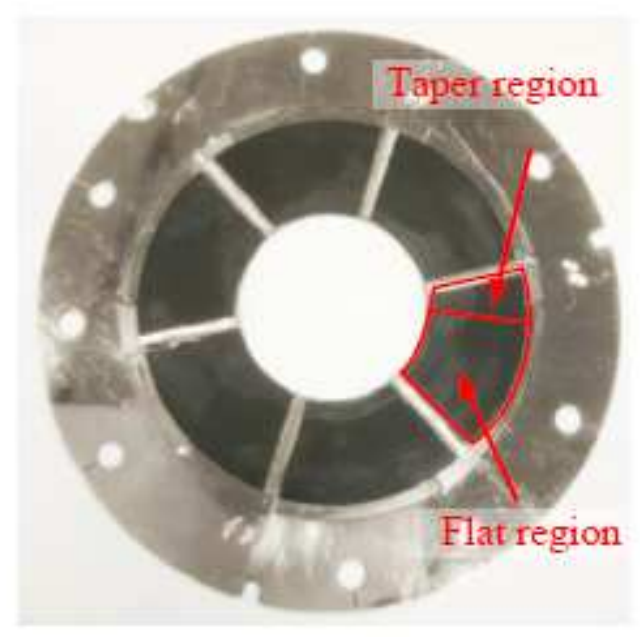

(b) After test

Figure 11

Photos of the tested bearing 

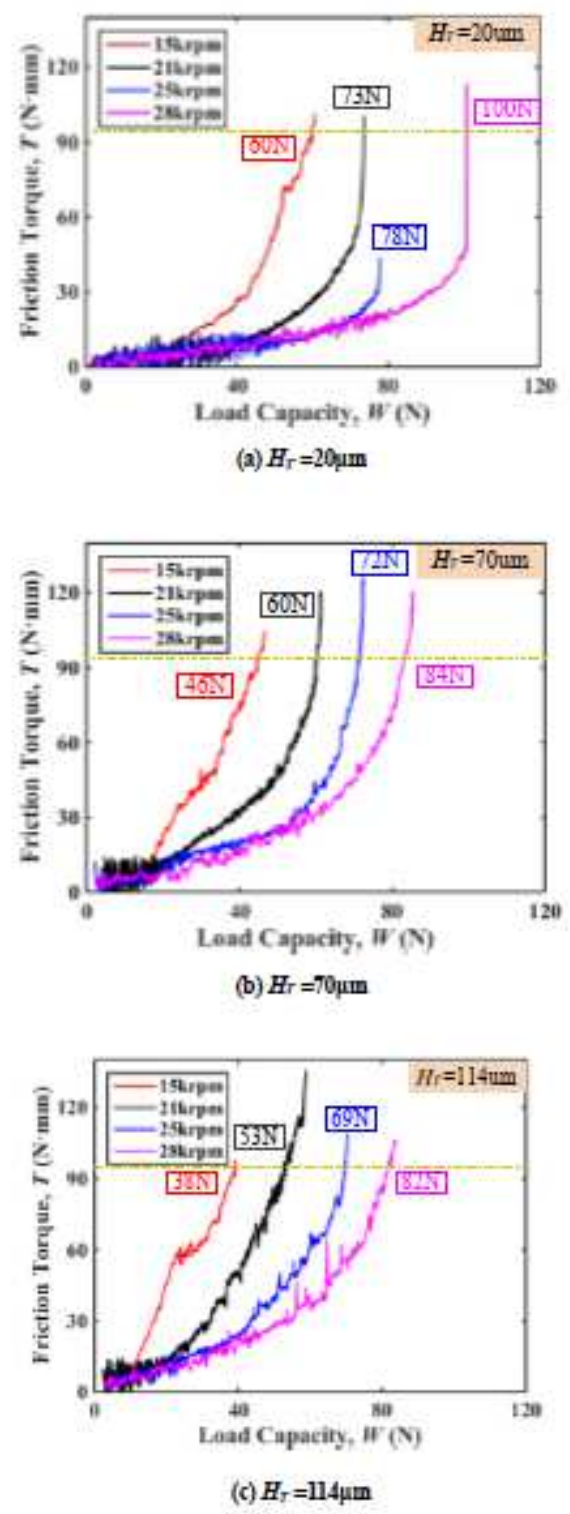

Figure 12

Friction torque versus load capacity for taper inlet height $\mathrm{HT}=20 \mu \mathrm{m}, \mathrm{HT}=70 \mu \mathrm{m}$ and $\mathrm{HT}=114 \mu \mathrm{m}$ at different rotor speed 


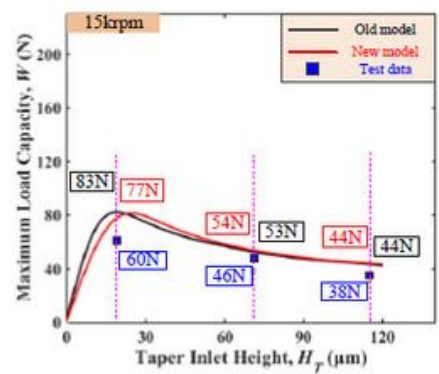

(a) $\omega=15 \mathrm{krpm}$

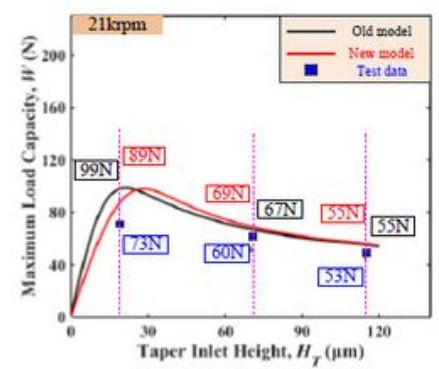

(b) $\omega=21 \mathrm{krpm}$

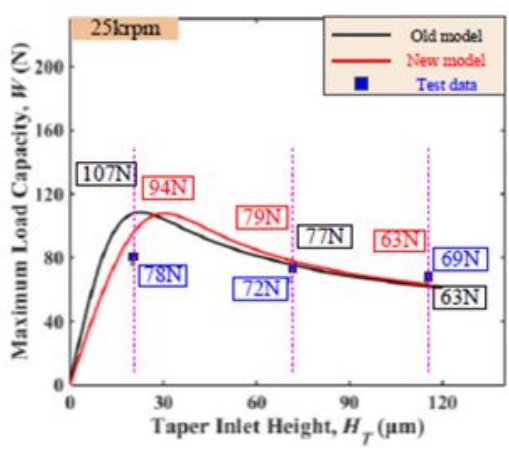

(c) $\omega=25 \mathrm{kr}$ m

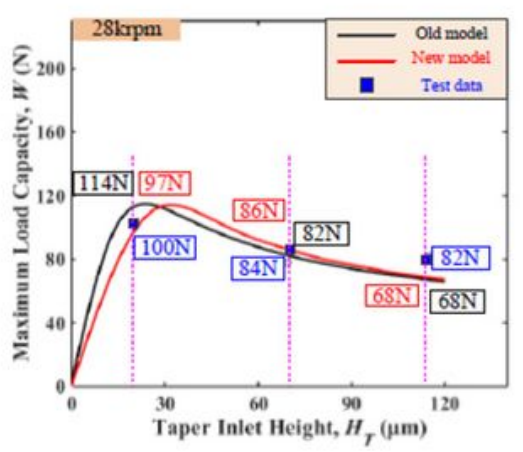

(d) $\omega=28 \mathrm{krpm}$

\section{Figure 13}

Maximum load capacity versus taper inlet height for different rotor speed under two models and test 